\title{
Power-Sharing Coalitions and Ethnic Armed Conflict*
}

\author{
Nils-Christian Bormann ${ }^{\dagger}$
}

\author{
Martin C. Steinwand:
}

\begin{abstract}
Which multiethnic coalitions reduce the risk of violent conflict? We argue that government leaders form larger ruling coalitions as the uncertainty over violent threats from radical sub-groups increases. We formalize this argument in a novel multi-actor model. Our game-theoretic approach illustrates how ruling elites reduce the risk of rebellion by sharing power with internally fragmented ethnic groups, while only slightly increasing the risk of coups. Empirically, we rely on a novel selection estimator and data on ethnic coalitions to investigate the predictions from our theoretical model. Our findings show that the conflict-reducing effect of power sharing increases once we consider the endogeneity of coalition formation and conflict, and that power-sharing coalitions are most effective when including internally fragmented groups. Our study advances our understanding of when power sharing works in ethnically divided societies.
\end{abstract}

WORD COUNT: 9'933

${ }^{*}$ We are grateful to helpful comments by Philipp Roessler, Carl Müller-Crepon, Yannick Pengl, Andrea Ruggeri, Statis Kalyvas, Kyle Beardsley, Laia Balcells, and Anne Sartori as well as audiences at Duke University, Oxford University, ETH Zürich, the 2016 Annual Meeting of the Peace Science Society, the 2017 Annual Meeting of the American Political Science Association, the 2018 Political Economy of Democracy and Dictatorship (PEDD) Conference in Muenster, Germany and the 2018 Annual Conference of the Network of European Peace Researchers.

${ }^{\dagger}$ Nils-Christian Bormann is Professor of International Political Studies in the Department of Philosophy, Politics \& Economics, Witten/Herdecke University, DE. Email: nils.bormann@uni-wh.de

${ }^{\ddagger}$ Martin C. Steinwand is Senior Lecturer in the Department of Government, University of Essex, UK. Email: martin.steinwand@essex.ac.uk 
Does governmental power sharing constitute an effective strategy to resolve intrastate armed conflicts between a government and ethnic rebel movements (Hartzell and Hoddie 2007; Mattes and Savun 2009; Roeder 2005; Gates et al. 2016)? While recent work suggests that governmental power sharing reduces the risk of ethnic armed conflict (Wucherpfennig, Hunziker and Cederman 2016; Johnson 2020), skeptics suggest that it raises the risk of coups and additional rebellions by excluded groups (Roessler 2011; Bormann and Savun 2018). To better capture the benefits and costs of ethnic power sharing, we turn our focus to ethnic coalitions - the ethnic groups included in the highest executive body of a state. We link the formation of ethnic coalitions to the risk of armed conflict and coups. Our study then answers the question which coalitions reduce intrastate conflict risk the most.

We formalize our theoretical ideas in an n-player game-theoretic model that departs from the unitary actor assumptions of governments and ethnic groups. First, we conceptualize governments as coalitions of ethnic group leaders. These leaders balance the risk of losing power through violent challenges such as armed conflicts and coups with the desire to maximize government control. Power sharing is thus endogenous to armed conflict (Wucherpfennig, Hunziker and Cederman 2016; Roessler and Ohls 2018). Second, some ethnic groups are internally fragmented into moderates and radicals. Where internally fragmented groups are excluded from power, radicals find it easier to mobilize group members for armed rebellion. Included group leaders anticipate the threat posed by excluded, fragmented groups to their rule, and bring them into oversized ruling coalitions to thwart rebellion. Yet even if fragmented groups are included into the central government, power sharing may not satisfy radicals' demands. In these cases, included groups initiate civil war as in 1975 Lebanon or stage a coup as in 1979 Uganda. Nevertheless our model predicts that ethnic power sharing with fragmented groups is more likely to avoid armed conflict and only minimally increases coup risk compared to coalitions that exclude fragmented groups.

Our empirical strategy closely approximates the theoretical model. We address the anticipation of violent conflict by estimating a selection model with coalition formation in the first stage, and ethnic armed conflict and coups in the second. Using data from 137 ethnically divided societies between 1946 and 2013 included in the Ethnic Power Relations dataset (Cederman, Wimmer and Min 2010), we identify ethnic coalitions in these countries. We then link the choice of the ruling coalition to the risk of conflict faced by the subsequently realized coalition. Three findings consistent with our theoretical model stand out: first, oversized coalitions are far 
more common than predicted by standard minimum-winning models, especially where the expected risk of conflict is likely to be high. Second, ruling coalitions that include a larger number of fragmented groups experience a lower risk of ethnic rebellion, and the effect increases once we account for the strategic selection of the ruling coalition. Finally, increasing coalition size only slightly increases coup risk.

\section{Ethnic Coalitions and Armed Conflict}

Does governmental power sharing successfully reduce the threat of armed conflict in states where ethnicity provides the basis for political mobilization? Some scholars answer this question affirmatively with respect to power-sharing institutions that mandate government inclusion (cf. Hartzell and Hoddie 2007; Johnson 2020), whereas others criticize them as ineffective (Roeder 2005; Gates et al. 2016). What unites advocates and critics is their focus on one-sizefits-all institutions that supposedly work or fail in both majority-minority states such as Turkey and in ethnically very diverse settings such as Sudan. Instead, we return to the original conceptualization of power sharing as coalitions between ethnic groups (Lijphart 1977).

Studying power sharing as a problem of coalition formation has several advantages. First, it widens our theoretical lens from dyadic government-armed group settings to multi-actor environments. In real-world cases such as Ethiopia, India, or Bolivia, different coalitions might be successful in reducing conflict risk. Second, studying ethnic coalitions empirically broadens the inquiry to include states where ethnic power sharing successfully brought stability in the absence of institutions. Existing work tends to focus on post-conflict states such as Lebanon or Bosnia, thus risking to base their results on cases with the highest likelihood of armed conflict. Third, focusing on ethnic coalitions brings into sharp relief trade-offs between the risk of armed conflicts and coups because leaders who build coalitions will balance the costs and benefits of a particular coalition choice relative to its alternatives.

We thus draw inspiration from a broad literature on government formation that investigates the alternative governments that political leaders might choose (e.g., Laver and Shepsle 1996). This work has predominantly treated stable democracies in Western Europe and North Amer-

ica. Accordingly, classic models of coalition formation require formal institutional commitment devices or bargaining protocols. Instead, our focus on ethnically divided societies with frequently weak institutions requires that political outcomes are self-reinforcing (also see Ace- 
moglu, Egorov and Sonin 2008). An ethnic coalition that brings stability implies that no ethnic group leader has incentives to take up arms to challenge the political settlement, whether they are inside or outside the government. Therefore, our model does not specify any population or group threshold for a coalition to retain power, and can thus account for minority governments as in Syria and for grand coalition as in Ghana.

Our theoretical approach concentrates on the determinants of the size and membership in the ruling coalition. We posit that group leaders face a trade-off when bargaining over these two parameters of the ruling coalition. For one, they aim to maximise their own influence within the government (Riker 1967). For another, group leaders seek to avoid losing power through violent challenges to their rule by other ethnic groups. We thus investigate the balancing act between maximizing total coalition payoffs while keeping the risk of armed conflict that might unseat the government - which we denote as political instability from now on - at acceptable levels.

Our modeling choices build on the core tenet of the formal conflict literature that fighting is costly and therefore ex-post inefficient. Thus, violent conflict arises either from commitment problems or information asymmetries (Fearon 1995). Following Cunningham (2013), we locate information asymmetries that arise during elite bargaining in the potential internal fragmentation of ethnic groups. Constructivist scholars of ethnic politics similarly note that ethnic identity is malleable, especially when group boundaries are cross-cut by alternative ethnic markers (Chandra 2012). We argue that competition among coethnic elites over the leadership of their group increases as the number of viable sub-groups increases, for example, when some group members can claim membership in a larger religious and a smaller linguistic category (McCauley 2014). To further distinguish themselves from their coethnic rivals, some elites might choose increasingly conflictual tactics and policies towards other ethnic groups. We call such elites radicals (e.g., Sambanis and Shayo 2013), and leaders that offer more cooperative stances to other ethnic groups moderates. ${ }^{1}$ Our theoretical analysis draws its main power from relaxing the unitary actor assumption of ethnic groups that characterizes much of the formal and informal conflict literature.

Turning towards leaders who try to form a governing coalition, we identify two principal

${ }^{1}$ Larson (2017) describes network integration in a similar way to our understanding of group fragmentation. Where groups are not integrated, group leaders cannot effectively sanction subgroups, and thereby have less control over their actions. 
sources of uncertainty that arise from the potential fragmentation of ethnic groups and possible coalition partners. The first source is whether a group contains any disaffected members and radical leaders that would engage in violence. The existence of radical factions is often not obvious to the leaders of other groups. The second source concerns the strength of a radical faction. Fundamentally, we assume that true support for radicals is only revealed once they use violence (Kydd and Walter 2006). Both sources of uncertainty introduce information asymmetries that are not easily overcome. Leaders of radical factions know that their sub-group exists and know its size. However, demanding a larger share of the pie for their sub-group is risky, because it can lead to oppression by their own main group leadership before violent action can increase their strength. In short, radical elites have strong incentives to misrepresent the group's true strength and to operate in the shadows (for a related argument, see Walter 2009, 248).

Meeting the subgroup's ambitions through the means of spoils politics is difficult, since in institutionally weak environments transfers to groups outside the governing coalition cannot be credibly promised. Unless powerful elites at the center want to risk rebellion by radical groups, they need to include internally fragmented groups in the governing coalition, in the hope that the spoils of being in power outweigh the incentives to use violence. However, as coalition size increases, the payoffs for coalition members decrease. In the following, we develop a model that incorporates this risk-return trade-off.

\section{A Model of Coalition Formation and Breakdown}

The set of actors $N$ consists of $n$ main groups $i, i \in 1,2, \ldots, n$, each of which can be fragmented and have up to one breakaway faction $\underline{i}$ (for a total number of actors between $n$ and $2 n$ ). ${ }^{2}$ In the baseline model without uncertainty we only consider the main groups $i$. All groups can be at peace, $P$, or in conflict, $\sim P$. In peace, a group can be either a member of a governing coalition $W$, or be excluded from government (denoted as member of $R$ ). Conflict is driven by struggle over the distribution of a finite pie, which is normalized to 1 . Any member of $W$ or $R$ (or any breakaway group) will try to initiate conflict if its expected payoff from fighting exceeds the utility from staying at peace. Any coalition must be self-enforcing and remains stable only if

${ }^{2}$ Groups and breakaway factions act as unitary actors. In practice, group leaders will make decisions for the group as a whole and there needs to be a mechanism to ensure group coherence. We assume that these collective action problems are solved. 
no groups choose to fight and eventually succeed in defeating the government.

The game begins by randomly choosing one group as the formateur that names the members of the coalition, not knowing with certainty if break-away factions exist. The choice of formateur is commonly defined by historical contingencies that vary between states but matter less for the within-state, between-coalition variation we are interested in (Wucherpfennig, Hunziker and Cederman 2016). For the same reason, we leave the details of within-coalition distributional politics for future work. The exact division of spoils frequently depends on historicallyinduced bargaining advantages that derive from (pre-)colonial policies or geographic and climatic features of a group's settlement region (Alesina, Michalopoulos and Papaioannou 2016; Vogt 2018).

After the formateur announces a schedule of transfers to coalition members and non-members, each group decides whether they accept the political settlement or initiate violent conflict. If a group accepts the settlement and it contains a potential breakaway group, the breakaway group decides if it is going to accept the settlement, in which case it receives a share of the transfers according to its pre-conflict group size. If the subgroup is dissatisfied with this outcome, it can attempt to initiate armed conflict in the hope of receiving a share of spoils that reflects its conflict strength. Initially, such attempts deterministically trigger intrastate conflict. ${ }^{3}$ We later relax this assumption and allow for probabilistic escalation to intrastate conflict.

If no groups or subgroups challenge the political settlement, or if no challenge succeeds, the government distributes payoffs as scheduled. In equilibrium, non-coalition members receive a transfer that is meant to keep them from rebelling. Coalition members in addition receive their share of the 'peace dividend', which consists of the surplus pie that is not needed to keep non-coalition members from rebelling (in equilibrium the peace dividend is equal to the social costs of fighting). If a breakaway faction challenges the settlement but fails to trigger intrastate conflict, the coalition stays together (minus the breakaway faction). If there is a successful challenge to the political settlement, the pie shrinks by $c$, the social costs of fighting. Conflict itself is represented as a costly lottery. The model is therefore not prescriptive of the nature of fighting. A realistic interpretation is that the breakaway group seeks to win government power and with it control of the contested pie. Technically, the winner is determined by a random draw, with the chance of victory being a function of its relative military strength. The payoff

\footnotetext{
${ }^{3}$ Deterministic conflict initiation is a widely-used simplification that helps us introduce the
} logic of the model (Hirshleifer 2001) 
for winning is the entire pie minus the social costs of fighting, $1-c$. All other groups receive 0 .

In our model, coalition formation reduces uncertainty and increases political stability over time. The formateur faces uncertainty over which groups are internally unstable, and tries to balance the cost of a larger coalition against the risk of a violent challenge from excluded, internally divided groups. Once the coalition forms, dissatisfied subgroups reveal their existence by trying to initiate conflict, which resolves uncertainty. However, information revelation itself is associated with challenges to political stability, which is why the formateur effectively seeks to limit the discovery of internally unstable groups by including them into the governing coalition.

\section{Baseline Model - No Uncertainty}

We present the model in two steps. The baseline scenario considers a situation without uncertainty, i.e. without any unstable groups. The main scenario introduces unstable groups, and illustrates the resulting risk-return trade-off between smaller and larger coalitions. Making the model more realistic in a third version, we model escalation to intrastate conflict probabilistically (see online appendix).

The payoff structure gives rise to the basic strategic logic of the game. The formateur proposes a transfer $t_{i}$ to each group. It has strong incentives to keep all groups from fighting, since the costs of conflict $c$ destroy the economic pie, which can be distributed in a way that increases every group's payoff (Fearon 1995). The resulting equilibrium payoffs are the following, ${ }^{4}$

$$
\begin{aligned}
E U_{i}^{*}(P, W) & =c / k+\frac{1-c}{n}, \\
E U_{i}^{*}(P, R) & =\frac{1-c}{n} \\
E U_{i}^{*}(\sim P) & =\frac{1-c}{n} .
\end{aligned}
$$

Groups outside the coalition receive a transfer $E U_{i}(P, R)$ equal to the conflict payoff, $E U_{i}(\sim P)$ that keeps them from fighting. The conflict payoff equals the utility of capturing the pie minus the social costs of fighting, $1-c$, times the chance of winning, $1 / n$. Since we set intra-coalition distributional politics aside, we assume that all groups $i$ have equal strength $1 / n$ and no further characteristics that helps to discriminate amongst them during coalition formation. Members of the coalition $W$ receive the conflict payoff and their share of the peace

\footnotetext{
${ }^{4} \mathrm{~A}$ proof is in the online appendix.
} 
dividend $c / k$, where $k=|W|$ is the size of the governing coalition. Given full information and no institutional requirements in the base game, in equilibrium the formateur forms a singleton coalition $(k=1)$ and keeps the entire peace dividend to itself, as predicted by Riker's (1967) size principle.

This result generates an important conceptual insight. If a formateur can target transfers to disaffected groups, no need to formally build coalitions exists. Incentives for coalitions only exist when the formateur's ability to target transfers varies between groups inside and outside the government coalition. In the next step we therefore treat formal coalitions as commitment device that allows the formateur to credibly promise transfers to coalition members. Our central argument is that the possibility of group breakup and the accompanying risk of conflict work against the size principle, endogenously resulting in coalitions that are oversized.

\section{Coalition Formation with Uncertainty}

To capture realistic coalition behavior in the absence of institutional majority requirements, we assume that the formateur can commit to transfers to coalition members, but less so to outsiders (cf. Ray 2007). In weakly governed countries, government leaders frequently rely on clientelistic structures and traditional group ties to deliver benefits to their supporters (Arriola 2009). Without access to these vertical ties, transfers to groups who are not included in government are more difficult and therefore less credible. Keeping the same payoff structure as in the base game (eq. 1 - 3), the formateur commits the peace dividend to coalition members, but excluded groups only receive a small transfer to keep them indifferent between peace and conflict.

In this scenario, the challenge for the formateur is to make the governing coalition sufficiently large to support peace, but small enough to maximize the payoffs of coalition members. This decision involves a risk-return tradeoff that results from two sources of uncertainty. First, the formateur does not know which groups are potential candidates for breakup and which ones are stable. Including a group in the coalition provides potential breakaway factions with higher transfers, making it less attractive to them to challenge the political settlement. Therefore, larger governing coalitions reduce the risk of breakaway and political instability from outside the governing coalition. However, the gains from holding power need to be shared more widely. Second, uncertainty about the relative strength of potential breakaway factions persists. Sub-groups that can mobilize particularly strong support in the case of conflict might 
still be dissatisfied with the added payoff of being inside the coalition.

Before characterizing the formateur's choice problem, we describe the payoffs that breakaway groups can achieve. Subgroups that do not challenge the settlement enjoy a share $a \in[0,1]$ of the transfers to their main group. ${ }^{5}$ A subgroup that breaks away seeks a larger share of the pie, reflecting its true strength $b \in[0,1]$, were $b>a .^{6}$

The formateur chooses the optimal coalition size $k$ by trading off the risk of conflict and the reward to coalition membership:

$$
\max _{k}(1-\operatorname{Pr}(\sim P))(c / k+(1-c) 1 / n)+\operatorname{Pr}(\sim P)(1-c) 1 / n
$$

The term $\operatorname{Pr}(\sim P)$ represents the probability that one or more groups break up and initiate conflict. If stability prevails, coalition members get to enjoy the peace payoff $c / k+(1-c) 1 / n$, otherwise they only receive the conflict payoff $(1-c) 1 / n$. The conflict probability $\operatorname{Pr}(\sim P)$ is defined as

$$
\operatorname{Pr}(\sim P)=\sum_{j=1}^{n} \operatorname{Pr}(j \text { groups unstable })((1-\operatorname{Pr}(\text { All } j \text { unstable groups in coalition }))
$$

$+\operatorname{Pr}($ All $j$ unstable groups in coalition $) \times \operatorname{Pr}($ at least one unstable group in coalition breaks up $))$.

Thus, conflict arises probabilistically as a result of the two sources of uncertainty discussed above. Uncertainty about the number and identity of unstable groups informs the first part of the equation, which captures the probability that some unstable groups are left out of the coalition. This probability is easily derived as groups at risk are determined by simple Bernoulli trials. ${ }^{7}$

${ }^{5}$ For coalition members, that's $a \times E U_{i}(P, W)$, and for non-coalition members $a \times$ $E U_{i}(P, R)$.

${ }^{6}$ The conflict payoff is $b \times E U_{i}(\sim P)$.

${ }^{7}$ The number of unstable groups $j$ follows a binomial distribution, with $j \sim B(n, \pi)$, to give $\operatorname{Pr}(j$ groups unstable). Parameter $\pi$ is the prior probability that a group is unstable. The probability that all unstable groups are captured in the coalition is distributed according to a hypergeometric distribution. Here, $w$ is the number of draws from the population of size $n$, and $j$ is the number of unstable groups that need to be successfully captured. Any unstable group left out the coalition breaks up and initiates conflict. 
The risk that unstable groups included in the coalition break apart despite receiving the coalition payoff forms the second source of uncertainty. For each unstable group, the pre-breakup share of group spoils is $a$, whereas the subgroup can secure share $b$ of the conflict payoff. We define the difference between the post-breakup and pre-breakup shares as $d=b-a$, and assume that $d$ follows a uniform distribution according to $d \sim U(0,1-a)$. The peace condition of subgroup $\underline{i}$ can be derived as ${ }^{8}$

$$
\begin{aligned}
E U_{i, s}(P, W) & \geq E U_{i, s}(\sim P), \\
a(c / k+(1-c) 1 / n) & \geq b(1-c) 1 / n, \\
d & \leq-\frac{a c n}{(c-1) k} .
\end{aligned}
$$

Given the distributional assumption on $d$, the probability that subgroup $\underline{i}$ does not break up is $\operatorname{Pr}\left(d \leq-\frac{a c n}{(c-1) k}\right)=F_{D}\left(-\frac{a c n}{(c-1) k}\right)=\frac{\left(-\frac{a c n}{(c-1) k}\right)}{1-a}$. Since conflict is initiated if at least one unstable coalition member breaks up, the overall probability of breakup within the coalition is simply the complement of the joint probability that none of the unstable groups break up, i.e. $1-\left(\frac{\left(-\frac{a c n}{(c-1) w}\right)}{1-a}\right)^{j}$.

\section{Coalition Size, Uncertainty and Conflict}

How do uncertainty and the size of the peace dividend affect the equilibrium choice of coalition size and conflict risk? We illustrate these relationships using simulations that vary the parameters of interest, while keeping all other parameters at fixed values, to observe how the equilibrium outcome changes. ${ }^{9}$ We first focus on the cost of conflict, which corresponds to the size of the peace dividend that accrues to the winning coalition if stability prevails. The second parameter of interest is the expected number of groups that harbor an undiscovered breakaway faction. ${ }^{10}$

\footnotetext{
${ }^{8}$ For details see online appendix.

${ }^{9}$ Comparative statics are difficult to obtain because of the combinatoric nature of probabilities. They involve differentiation of the binomial and hypergeometric probability mass functions, which results in expressions involving harmonic numbers.

${ }^{10}$ The model has a unique equilibrium. A continuous objective function on a compact set guarantees existence of a global maximum. The singleton global maximum is unique.
} 


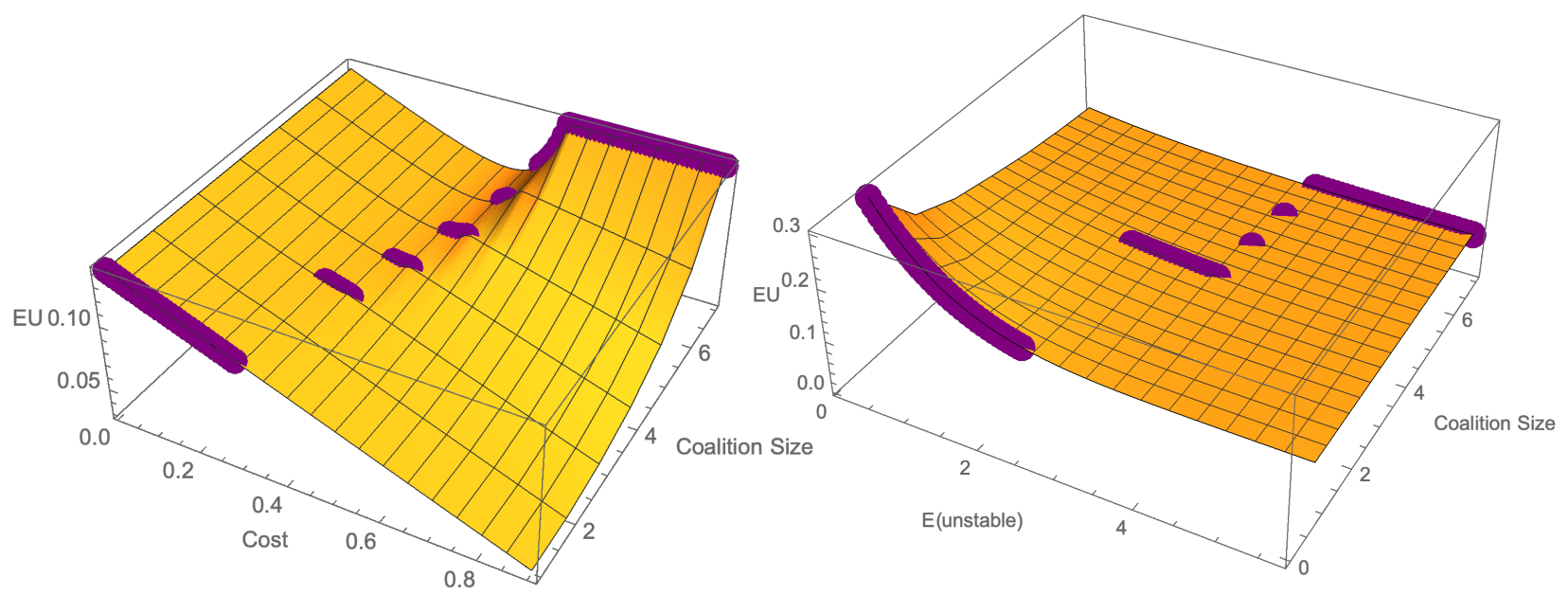

(a) Peace Dividend: Varying Cost

(b) Breakaway Factions: Varying Uncertainty $\pi=0.5, n=7, a=0.45$ $c=0.4, n=7, a=0.45$

The left graph in Figure 1 shows how the utility of the formateur changes as a function of the cost of conflict and coalition size. The equilibrium choice of coalition size for each value of $c$ is marked with dark dots. The level of uncertainty is fixed to $\pi=0.5$, corresponding to an expected number of $n \pi=3.5$ potentially unstable groups. ${ }^{11}$ The graph shows that equilibrium coalition sizes increase as the cost of conflict goes up. The intuition is that as conflict increases in cost, the peace dividend shared by coalition members grows as well. Therefore the opportunity costs of fighting increase, and it pays to reduce conflict risk by making coalitions larger, while sharing the payoffs from the peace dividend among a larger numbers of coalition members. At the extremes, conflict is either so expensive that a grand coalition forms, or so cheap that a single-group government rules.

The right graph in Figure 1 ties the risk-return logic explicitly to the argument that uncertainty about unstable groups is a driver of coalition size. Now, we fix the cost of conflict at $c=0.4$, while allowing $\pi$, and thus the induced expected number of unstable groups, $E$ (unstable) $=n p$, to vary. First, the utility of being in government decreases as uncertainty goes up, as the risk of conflict reduces the benefits from holding power (in expectation). Second, as the expected number of unstable groups goes up, the formateur counteracts increasing instability by choosing larger coalition sizes, but has to share the spoils of holding office more widely.

\footnotetext{
${ }^{11}$ The choice of $n=7$ is somewhat arbitrary, but enhances clarity of exposition by providing a large range of coalition sizes not confirming to the minimum winning ideal.
} 
In order to generate predictions about conflict outcomes, we next investigate the conflict probabilities induced by the formateur's choice of equilibrium coalition size. Figure 2 shows the probability that one or more dissatisfied breakaway factions initiate conflict, as a function of the cost of fighting (left panel) and uncertainty (right panel). The different colored dots correspond to different equilibrium coalition sizes. ${ }^{12}$

Figure 2: Equilibrium Probability of Conflict Initiation

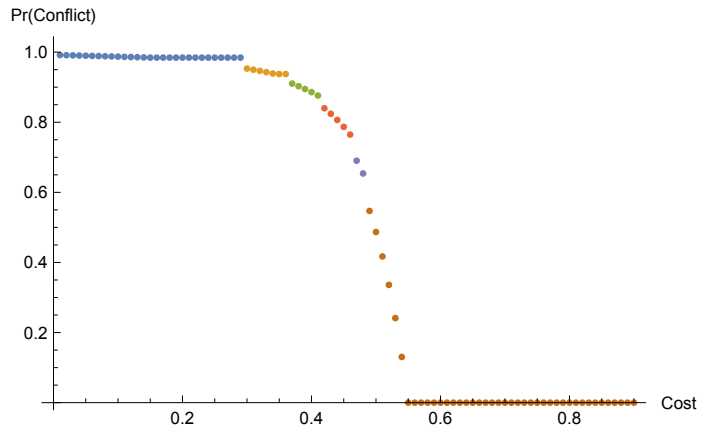

(a) Peace Dividend: Varying Cost;

Colors represent equilibrium coalition sizes; $\pi=0.5, n=7, a=0.45$.

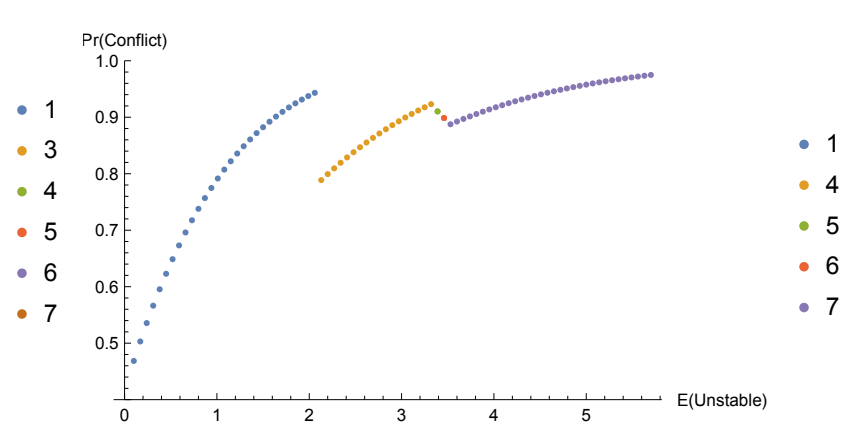

(b) Breakaway Factions: Varying Uncertainty; Colors represent equilibrium coalition sizes; $c=0.4, n=7, a=0.45$.

Beginning with the left panel, increasing costs of conflict imply a monotonically decreasing probability of conflict, alongside increasing coalition sizes. As fighting becomes more destructive, the worth of political stability to coalition members increases. Hence it pays to spread the spoils from coalition membership more widely to reduce the risk of conflict. This insight generates the first empirical implication of our model. Oversized coalitions should become more frequent in times and places where the costs associated with coalition failure increase. Hence, oversized coalitions should be a more prominent feature in developing countries, where state institutions have low capacity and elites have to fear losing their freedom, property or even lives if they lose office (Bueno de Mesquita et al. 2003, 28).

The boundary cases in the left panel illustrate how coalition choice and political reality are connected in a wide range of scenarios. While grand coalitions have the potential to reduce the risk of conflict, they do so with certainty only if the costs of fighting are overwhelmingly high (for $c \geq 0.55$ ). However, there remains a range of values of $c \in[0.49,0.54]$ for which conflict

\footnotetext{
${ }^{12}$ The large conflict probabilities depicted in Figure 2 derive from the simplifying assumption that very small splinter groups mechanically trigger conflict that involves all groups. In the online appendix, we drop this assumption and model conflict initiation probabilistically. Our model becomes more complex but its central insights remain unchanged.
} 
is possible. This scenario corresponds to well-known cases such as Yugoslavia and Lebanon, in which grand coalitions could not prevent civil war onsets. On the other extreme, as the costs of fighting go towards zero, the optimal coalition size drops below 4 and minority governments form. Once $c$ is below 0.3 , the formateur prefers to govern alone, since lowering the risk of conflict is not worth the price of inducing other groups to join the coalition and sharing the already small peace dividend. This scenario describes cases of state failure such as Afghanistan and Sierra Leone in the 1990s, where different ethnic rebel factions ruled separate territories without any desire to share meaningful power at the center.

The right panel of Figure 2 ties conflict risk to uncertainty. Three characteristics stand out. First, as the expected number of unstable groups goes up, equilibrium coalition sizes increase. Second, the probability of conflict increases smoothly as a function of uncertainty as long as the coalition size remains unchanged, but it jumps downwards when the coalition size goes up. The third observation is that larger coalitions do not necessarily result in levels of conflict risk that are low in absolute terms. The left panel showed a monotonic negative relationship between coalition size and conflict probability, but uncertainty was kept constant. However, the choice of coalition size is a reaction to instability among political groups, making coalition size endogenous to the ex-ante probability of conflict. The right panel therefore shows that larger coalitions form in environments in which group instability and the risk of political instability tend to be high in the first place.

The comparative static exercise in Figure 2 generates two important testable insights. First, oversizing coalitions is a reaction to underlying political instability, both in the form of high costs of conflict and a large number of potentially unstable groups.

Hypothesis 1 Oversized and grand coalitions are more likely in societies with high underlying political instability.

Second, there exists a complex relationship between coalition size and the observable probability of conflict, which is in part driven by the endogenous choice of coalition size as a function of the levels of uncertainty in the political system. The right panel of Figure 2 shows that conflict probabilities jump downward when coalition sizes increase. However, coalitions of different sizes can be associated with the same probability of conflict, since coalition sizes grow alongside conflict risk as the expected number of unstable groups goes up. Accordingly, 
we have no clear unconditional prediction of the effect of coalition size on the risk of conflict. In order to directly test the key argument that larger coalitions reduce the probability of conflict, it is therefore necessary to account for the endogenous nature of coalition formation: The relevant counterfactual compares coalitions of different sizes, while stripping out the higher ex-ante risk of conflict that drives the formation of larger coalitions. More inclusive, larger coalitions should perform better in preserving political stability than smaller ones, specifically if they include internally fragmented groups, but this relationship can only be uncovered when empirically accounting for the factors that drive coalition formation.

Hypothesis 2 Considering endogenous coalition choice, larger coalitions that include fragmented groups are associated with a lower observable probability of armed conflict than coalitions with fewer internally fragmented groups.

\section{Internal Versus External Instability}

So far we have treated the breakup of any group as a threat to political stability, regardless whether a group is within or outside the governing coalition. However, violent challenges to the government by excluded groups, or rebellions, differ from internal challenges, i.e., coups. The logic that equates larger coalitions with reduced conflict only applies to excluded groups. Larger coalitions allow to pull potentially unstable groups into the government to satisfy splinter groups, but sharing the spoils of government more widely may increase coup risk.

Consider Figure 3, which is based on the same configuration as the right panel of Figure 2, but breaks down the total probability of conflict into risk stemming from groups inside, i.e. coup risk (blue line), and outside the governing coalition (yellow line). As the number of unstable groups increases, the discontinuous downwards jumps in the total probability of conflict - corresponding to increases in equilibrium coalition size - mainly result from reductions in the risk of breakup of outside groups. Coup risk initially increases only slowly. Once the expected number of unstable groups reaches 3.5, coup risk goes up to 32 percent (for coalition size $k=6$ ). Moving to an expected number of unstable groups of 3.6, the model predicts the formation of a grand coalition $(k=7)$. For this boundary case, coup risk jumps to 89 percent. Since the only source of conflict lies withing the coalition once all groups are included, these higher risks are unsurprising. 
Figure 3: Instability Deriving from Rebellion and Coups

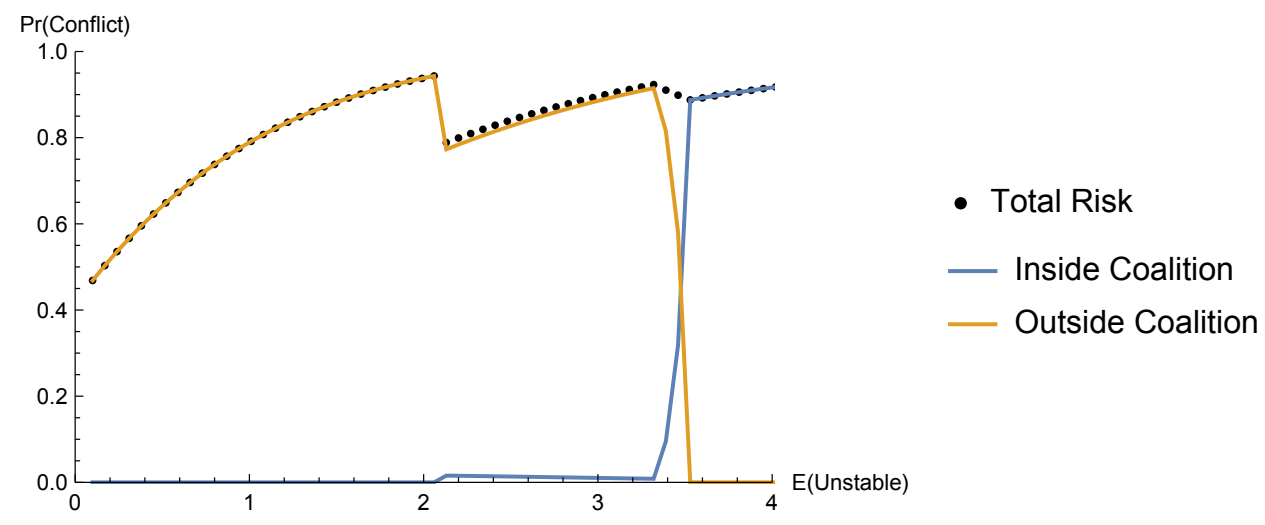

Figure 3 illustrates that the moderating relationship between coalition size and the risk of conflict described in $\mathrm{H}_{2}$ applies only to external challenges to the government, but not for coups. The expected relationship between coalition size and coups is positive. As our analysis exaggerates absolute effect sizes, the relative contribution of coup risk to the overall probability of conflict is low, except for the boundary case. We therefore expect the empirically observable relationship between coalition size and coups to be relatively small.

Hypothesis 3 Considering endogenous coalition choice, larger coalitions that include fragmented groups are associated with a weakly larger observable probability of coups than coalitions with fewer internally fragmented groups.

\section{Research Design}

Our theoretical model describes how elites form coalitions in anticipation of future challenges and thereby affect the risk of conflict. Statistical models of armed conflict or coup risk almost always ignore the alternative governments which elites might form before conflict onset. Even when modeling many structural and situational characteristics that governments face, these models likely suffer from some form of selection or omitted variable bias.

To overcome this challenge, we use a two-stage statistical estimator that first models the selection of ethnic groups into government, and second the risk of conflict onset. Developed by Chiba, Martin and Stevenson (2015) to tackle selection bias in studies of government duration in European parliamentary democracies, we adjust their estimator to model the time until a government experiences its first violent challenge as either an ethnic armed conflict or a coup 
d'etat. $^{13}$

We follow a long literature on coalition formation spearheaded by Martin and Stevenson (2001) in using conditional choice models. These models estimate the choice situation of elites by calculating probabilities for all potential government coalitions in one country at multiple points in time. Like Chiba, Martin and Stevenson (2015), we use the conditional logit, a fixed effects logit that accommodates a variable number of choices between potential governments at different formation opportunities. The estimator weighs each opportunity equally even if some states such as India feature complex ethnic divisions and hundreds of thousands of potential governments, whereas more homogeneous countries such as Turkey offer elites only the choice between three government alternatives: Turkish or Kurdish single-group rule, and a two-member coalition.

Next, we estimate the time until excluded groups or coalition members violently challenge the government. This duration is affected by a variety of observable factors highlighted in the extensive literature on civil wars (e.g., Hegre and Sambanis 2006) and coups (e.g., Roessler 2011). Beyond such observables our theory highlights that the anticipation of conflict plays a central role for its occurrence. In a related argument focused on coups, Roessler (2011) shows that rulers eject ethnically distinct rival elites from government coalitions to forestall any intragovernmental challenge.

We model the selection process induced by unobservable anticipation effects by linking the coalition formation and conflict risk stages with a Gaussian copula link function (Trivedi and Zimmer 2005). ${ }^{14}$ Chiba, Martin and Stevenson $(2015,7)$ describe a copula as "a function that parameterizes the dependence between univariate marginal distributions to form a joint distribution function." Copulas allow us to link univariate distributions from different statistical families as long as these distributions are known. To check whether our results are an artefact of modelling choices, we estimate the duration stage with a Weibull and with a Log-logistic distribution.

\footnotetext{
${ }^{13}$ Although it is principally possible to model the second stage as regular binary choice situation between conflict and no conflict, the differences between a duration model and binary choice model are negligible (see Beck, Katz and Tucker 1998).

${ }^{14}$ The Gaussian copula link allows the dependence parameter between the formation and duration stages to take on values between -1 and 1 . Other copula functions are more restrictive.
} 


\section{Data}

We investigate government coalitions between ethnic groups rather than political organizations such as parties. Our focus on ethnic groups has three key advantages: First, a long literature demonstrates the importance of ethnic inclusion in the central government for the risk of ethnic armed conflict (Cederman, Wimmer and Min 2010) and coups (Roessler 2011). Second, it allows us to extend our investigation beyond democratic regimes to autocracies, where coalition dynamics are just as relevant but do not necessarily take place between political parties (Magaloni 2008). Third, a focus on ethnic groups facilitates detecting multiethnic coalitions that might otherwise remain hidden because they occur within individual parties (Bogaards 2014).

We derive both potential coalitions and the duration of the formed coalition from the 2014 version of the Ethnic Power Relations data (EPR 2014) (Cederman, Wimmer and Min 2010; Vogt et al. 2015). The dataset provides information on the political relevance of ethnicity for all states where group leaders advance political claims on behalf of their coethnics, or where the state politically discriminates against any group. EPR also codes the relative population share of groups, and most importantly, their power status on an ordinal scale that ranges from "discriminated" to "monopoly power" (Vogt et al. 2015, 1331). We consider ethnic groups that are included in the highest executive body of the state to be part of the governing coalition. ${ }^{15}$

Our unit of analysis in the formation stage is the formation opportunity or the set of all potential ethnic coalitions that could form. We identify new formation opportunities under two conditions. First, shocks to the bargaining environment alter the balance of power between ethnic groups in the country. These instances include changes in group size, in the set of politically relevant ethnic groups in a state, or relative changes to the influence of groups within the ruling coalition that do not alter its composition, such as the change of Prime Minister from one group to another. Changes in the composition of the government coalition constitute the second type of formation opportunities. We observe such alternation when at least one group leaves or enters the government coalition. Overall, our dataset contains 7,271,411 potential governments across 542 formation opportunities in 137 ethnically divided states between 1946 and 2013 .

Our main outcome variable in the selection stage is the actual coalition chosen by political leaders as coded in the EPR 2014 data. We add the following explanatory variables to

\footnotetext{
${ }^{15}$ Executive bodies include presidential and prime ministerial cabinets in democracies, and royal courts, communist central committees, or military juntas in autocracies.
} 
our model: binary indicators of the type of government that elites form (single-group rule vs minimum-winning vs oversized coalitions) proxy the risk-return trade-off described in our theoretical model. ${ }^{16}$ The count of the number of included groups provides more precise information on size differences within oversized coalitions. A dummy variable that flags whether or not the government has included groups with a history of rebellion proxies one source of the risk of future violent challenges (see Cederman, Wimmer and Min 2010, 97). We model a potential formateur advantage with a dummy indicator that records whether or not the largest group in a state is included (Francois, Rainer and Trebbi 2015; Ariotti and Golder 2018).

We add the the number of linguistic and religious segments that cross-cut ethnic groups for each potential coalition as our main indicator of group incoherence. Drawing on data by Bormann (2019), our measure adds information on potential internal splits that ethnic groups bring into the coalition. Each group can contain multiple cleavages. Muslims in India, for example, are internally divided along linguistic lines whereas the Yoruba in Nigeria include both Christian and Muslim segments. Finally, fixed effects for each formation opportunity capture unobserved between-country and over-time variation, such as time and place-specific strategic calculations by leaders.

For identification purposes, we require one variable that is included in the selection stage of government formation but not in the outcome or conflict stage. Additionally, this variable should explain conflict only indirectly through its effect on coalition formation. We choose the population share of groups included in the previous government that returns to the government after elites reshuffle the ruling coalition (see Chiba, Martin and Stevenson 2015, 53, fn.17, for a similar strategy). ${ }^{17}$ Identification succeeds when the variable added to the selection stage is a strong predictor of the selected unit and only influences the outcome of interest through the selection. The population share of previously included groups meets both criteria. First,

\footnotetext{
${ }^{16}$ Empirically, we define minimum-winning coalitions as those that enjoy the support of at least $50 \%$ of the population but minimise the number of groups and the share of the population that brings them above the $50 \%$ threshold. Oversized coalitions comprise all remaining governments that are greater than the minimum winning coalition. Our baseline are minority governments.

${ }^{17}$ To avoid losing a large number of observations at the beginning of our sampling period, we coded the lagged population share variable for all governments before 1946 or the independence of states.
} 
it has a strong effect on coalition formation. Second, it is difficult to imagine how the share of previously included groups could affect armed conflict or coup onset other than through the formation of the new coalition.

In the conflict stage, our unit of analysis is the realized government and our outcome variable is the time until the this government experiences a violent challenge. We distinguish between the competing risks of ethnic armed conflicts with at least 25 battle-deaths per year (Gleditsch et al. 2002; Themnér and Wallensteen 2014) and coup attempts (Powell and Thyne 2011). We investigated all country-years that included both an armed conflict and a coup onset, and only coded the event that occurred first in that year. ${ }^{18}$

Departing from existing work in conflict research (e.g., Hegre and Sambanis 2006; Cederman, Wimmer and Min 2010), we only code the first conflict onset after a formation opportunity. ${ }^{19}$ We do so for both theoretical and methodological reasons. Theoretically, our model predicts that elites anticipate violent challenges and adjust their government coalition accordingly before conflict breaks out. Our argument thus has little to say about repeated small-scale rebellions that do not pose a direct threat to ruling elites, such as many secessionist conflicts. Methodologically, the Chiba, Martin and Stevenson (2015) selection estimator does not allow us to estimate the risk of repeated failures. In fact, we only observe one outcome for each formation opportunity. As we will demonstrate below, we nevertheless recover many of the established findings in the literature. Overall, our sample retains 74 ethnic armed conflict onsets and 133 coup attempts.

Our main explanatory variable is the number of linguistic and religious cleavages in the coalition that proxies the number of internally fragmented groups in a coalition. Additionally, we control for the number of ethnic groups represented in the ruling coalition and the population share of the included population. Adding both variables helps us distinguish governments that represent a large part of the population but are ethnically narrow, from governments of similar sizes with far more diverse members. We expect the size of the included population to be negatively associated with armed conflict onset as fewer individuals feel aggrieved and the government can rely on greater manpower to deter external challenges (Cederman, Wimmer

\footnotetext{
${ }^{18}$ In our main analysis, eight country-years featured both a coup and an ethnic armed conflict onset. Coups preceded armed conflicts in half of the cases.

${ }^{19}$ If no onset occurs until a new government forms or our sampling period ends, we code the observation as right-censored.
} 
and Min 2010,96). In contrast, we expect a larger number of included groups to lead to greater infighting and coup d'etats as the size of transfers to each group decreases.

We also include two binary indicators that flag whether or not former rebels and the largest group are included in the ruling coalition. Past armed conflicts robustly predict future conflict (Cederman, Wimmer and Min 2010, 97) but including former rebels in power sharing pacts should decrease the likelihood of further conflict (Hartzell and Hoddie 2007; Mattes and Savun 2009). Including the largest group in a country into government should address the biggest possible grievance and reduce the risk of ethnic armed conflict. As rebellions become less likely, coups might proliferate as a means to challenge elites from the largest group, which cannot be overcome on the battle field. Finally, our models include the most robust control variables from the civil war literature: country-level GDP per capita and population size (see Hegre and Sambanis 2006). ${ }^{20}$

\section{Empirical Evidence}

Our first piece of evidence is descriptive. Figure 4 displays the share of oversized and grand ethnic coalitions by world region between 1946 and 2013. East Asia and the West (the Americas, Australia, New Zealand, and all EU member states) exhibit the lowest share with about $20 \%$ of all country-years ruled by oversized or grand ethnic coalitions. ${ }^{21}$ Sub-Saharan Africa features the highest share with more than $60 \%$ of country-years experiencing large coalition rule. In line with $H_{1}$, elites form oversized or grand ethnic coalitions more frequently in the politically unstable states of South Asia, Africa, and the Middle East than in more stable states. ${ }^{22}$ Put differently, ethnic coalitions occur in those regions that account for the vast majority of political violence in the world (Themnér and Wallensteen 2014).

\footnotetext{
${ }^{20}$ All of our variables are measured at the time when the coalition forms. Only GDP and population size might change their value as time progresses. Coding the value of GDP and population size at the time of conflict onset or right-censoring does not affect our results.

${ }^{21}$ Recall that our data do not provide information about the number of parties in the executive, but the number of ethnic groups represented in the executive.

${ }^{22}$ The EPR dataset identifies oversized coalitions in Belgium, Canada, Spain, and the United Kingdom — states that have experienced political instability related to ethnic divisions and even armed conflict.
} 
Figure 4: Share of oversized and grand ethnic coalitions by world region, 1946-2013

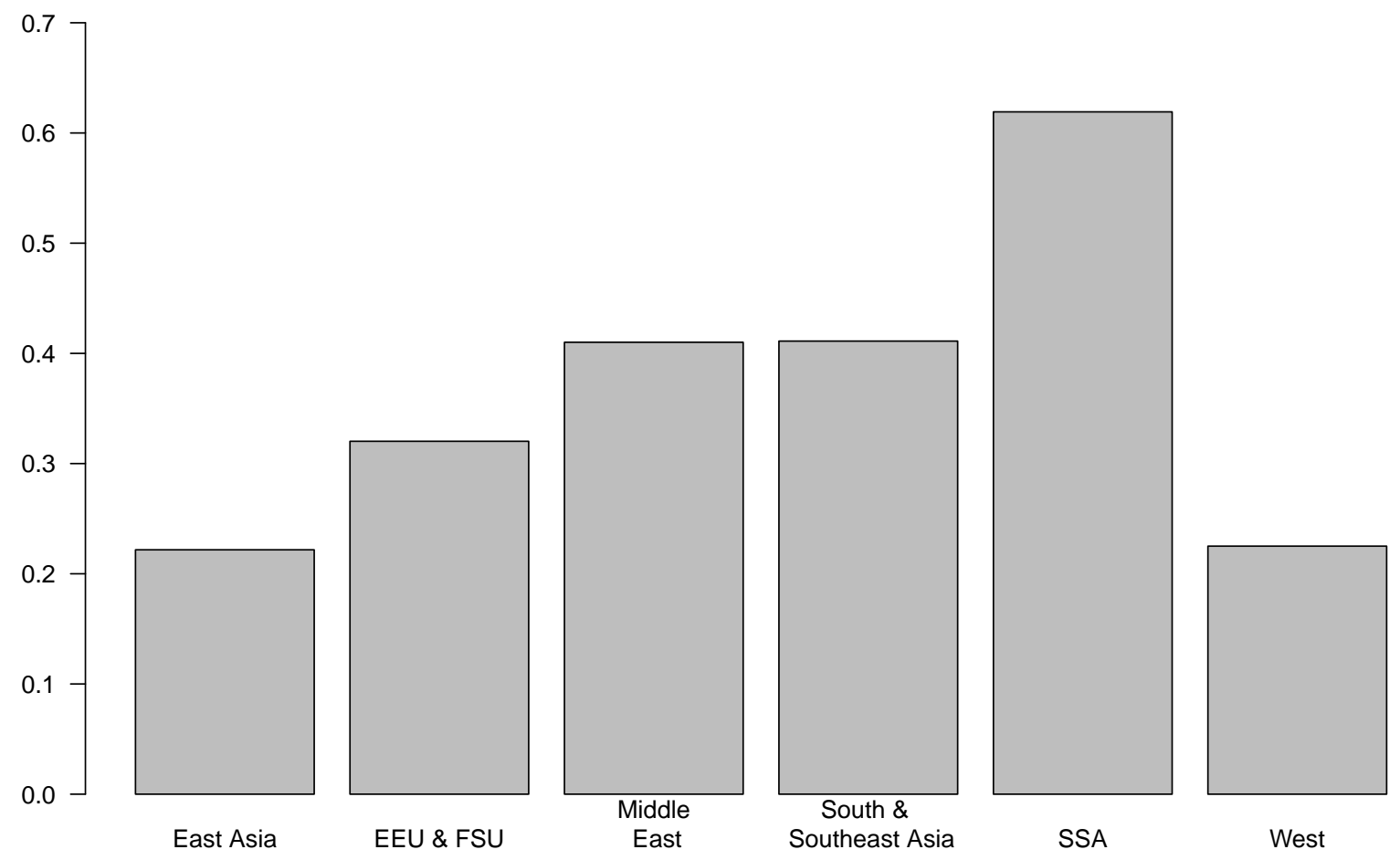

We detect a similar correlation between increases in coalition size and decreases in the capacity of states to fend off external challengers when investigating the changes brought about by the end of the Cold War (Figure 5). As developing states around the globe suddenly lost financial, ideological, and military support from the Soviet Union and United States, domestic leaders faced an increased risk of rebellion, and possibly losing power if they did not broaden their domestic support base (Kalyvas and Balcells 2010, 421-2). The Ethiopian Derg regime, for example, was defeated and replaced by the multiethnic Ethiopian People's Democratic Liberation Front shortly after Soviet weapons and financial transfers stopped. In line with $H_{1}$, governments that face higher costs of conflict due to decreasing capacity, form larger, more inclusive coalitions.

We now turn to the link between coalition formation and conflict. Table 1 displays four specifications that estimate the risk of ethnic armed conflict (Models 1\&2) or coup onset (Models 3\&4). Models 1 and 3 display estimates from a normal single-equation duration model, while Models 2 and 4 show the results from the two-stage coalition selection model. ${ }^{23}$ In keeping with established practise in models of conflict onset, the estimated coefficients are hazard betas. Positive coefficients indicate an increase in the risk of armed conflict or coup onset while

\footnotetext{
${ }^{23}$ As the selection stage is almost identical to the results reported by Bormann (2019), we only showcase the model in Table A1 in the online appendix.
} 
Figure 5: Share of oversized and grand coalitions before and after 1990.

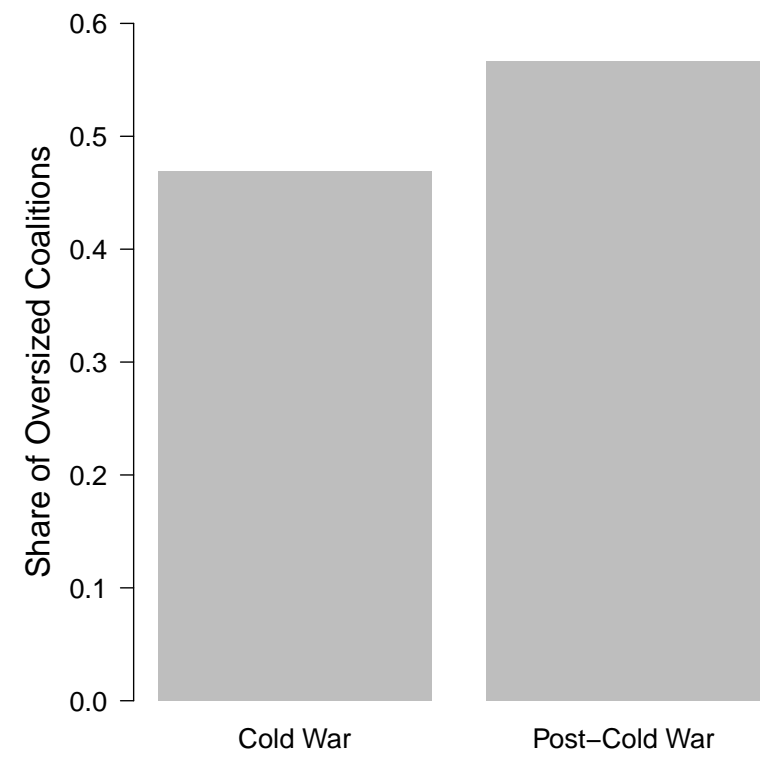

negative coefficients show a decrease.

In our analysis of armed conflicts, we observe strong selection effects as indicated by the differences between Models 1 and $2 .{ }^{24}$ In line with $H_{2}$, the estimated effect of fragmented groups inside the coalition decreases the onset risk of rebellion, and it almost doubles in size when considering strategic coalition choice in Model 2. In contrast, previously used indicators of inclusion which do no account for group fragmentation, such as the relative share of the included population or the number of groups in government, become weaker once we model coalition selection..$^{25}$

A second important finding is the negative and statistically significant $\rho$ estimate in Model 2. This parameter captures the correlation between the error terms in the coalition formation and conflict stages. The negative correlation indicates that unobserved variables that affect coalition choice decrease the risk of ethnic armed conflict onset. We argue that this correlation captures the unobservable strategic considerations by elites to form coalitions that reduce the risk of armed conflict. This selection effect mirrors insights by Wucherpfennig, Hunziker and Cederman (2016), who find a similar effect for inclusion and armed conflict in former British and French colonies with an instrumental variable approach at the group level. Our model generalizes their finding beyond former colonies and the government-ethnic group-dyad towards

\footnotetext{
${ }^{24}$ Likelihood ratio tests reject the null hypothesis of no difference $(p<.05)$.

${ }^{25}$ The overall effect of group size in our statistical model is a combination of these three indicators. Reassuringly, they jointly predict an increase in the time until the first onset, in line with our theory and previous findings.
} 
Table 1: Armed conflict and coup onset risk after government formation, 1946-2013.

\begin{tabular}{lcccc}
\hline \hline & \multicolumn{2}{c}{ Ethnic Armed Conflicts } & \multicolumn{2}{c}{ Coup Attempts } \\
& $(1)$ & $(2)$ & $(3)$ & $(4)$ \\
\hline \# of Incl. Segments & $-0.364^{*}$ & $-0.638^{* *}$ & -0.180 & 0.006 \\
& $(0.173)$ & $(0.219)$ & $(0.121)$ & $(0.118)$ \\
\# of Incl. Groups & $0.133^{*}$ & 0.039 & 0.014 & $0.098^{*}$ \\
& $(0.057)$ & $(0.106)$ & $(0.063)$ & $(0.047)$ \\
Share of Incl. Pop. & $-1.646^{*}$ & -1.244 & 0.442 & -0.002 \\
& $(0.752)$ & $(0.947)$ & $(0.592)$ & $(0.586)$ \\
Past Rebels in Coal. & $0.798^{* *}$ & $0.882^{*}$ & -0.327 & -0.119 \\
& $(0.304)$ & $(0.382)$ & $(0.343)$ & $(0.251)$ \\
Largest Group & 0.571 & 0.770 & -0.552 & -0.614 \\
& $(0.512)$ & $(0.622)$ & $(0.395)$ & $(0.323)$ \\
Log(GDP p.c.) & $-0.445^{* * *}$ & $-0.478^{* * *}$ & $-0.577^{* * *}$ & $-0.492^{* * *}$ \\
& $(0.108)$ & $(0.124)$ & $(0.080)$ & $(0.062)$ \\
Log(Population) & $0.286^{* *}$ & $0.267^{* *}$ & $-0.134^{*}$ & $-0.087^{*}$ \\
& $(0.094)$ & $(0.103)$ & $(0.068)$ & $(0.039)$ \\
Constant & $-4.173^{*}$ & $-4.786^{* *}$ & $3.878^{* *}$ & $3.530^{* * *}$ \\
& $(1.680)$ & $(1.706)$ & $(1.268)$ & $(0.432)$ \\
Error Correlation $(\rho)$ & & $-0.327^{*}$ & & $0.231^{* *}$ \\
& & $(0.160)$ & & $(0.077)$ \\
Log(Duration Dependence) & -0.136 & 0.035 & $-0.159^{*}$ & $-0.407^{* * *}$ \\
& $(0.093)$ & $(0.106)$ & $(0.068)$ & $(0.112)$ \\
\hline$\ell$ & -1797.136 & -1794.576 & -2017.666 & -2013.071 \\
\# of Countries & 137 & 137 & 137 & 137 \\
\# of Failures & 74 & 74 & 133 & 133 \\
Governments at Risk & 542 & 542 & 542 & 542 \\
Potential Governments & $7,270,134$ & $7,270,134$ & $7,270,134$ & $7,270,134$ \\
\hline \hline
\end{tabular}

${ }^{*} \mathrm{p}<0.05 ;{ }^{* *} \mathrm{p}<0.01 ;{ }^{* * *} \mathrm{p}<0.001$

Displayed estimates are coefficients. Positive values indicate increase in risk of conflict/coup onset. Standard errors in parentheses. 
dynamic coalition formation.

Turning to the coup specifications in Models 3 and 4, we again find strong selection effects. ${ }^{26}$ Increasing the number of groups in a coalition yields a slight increase in coup risk after accounting for selection effects in line with $\left(\mathrm{H}_{3}\right)$. The result seemingly supports earlier findings by Roessler (2011). However, the positive error correlation $(\rho)$ in Model 4 implies that political elites seem to tolerate coup risk once we consider coalition formation. We can only speculate why this is the case: investigating coup attempts rather than successful coups could drive this selection effect. The far higher number of observed coup attempts relative to armed conflicts might indicate that political leaders in ethnically divided societies are more risk-tolerant of coups relative to rebellions, and form ruling coalitions to avoid the latter.

As the estimated effects of our control variables correspond to earlier findings, we do not discuss them further. Instead, we briefly discuss duration dependence: whereas the risk of armed conflict onset remains constant as time passes in Models 1 and 2, we uncover evidence of negative duration dependence in Models $3 \& 4$. Put differently, coup attempts become less likely as coalitions stay longer in office. We find the same negative estimation of duration dependence when estimating duration with the log-normal distribution (Table A4), which allows non-monotonic hazards. The latter result implies that coup duration increases for a short while after coalition formation but then quickly decreases as predicted by Svolik $(2009,479)$.

In our online appendix, we explore the robustness of the results to measurement error in the outcome variable, omitted variable bias, and model dependency. Using civil war rather than armed conflict onsets by Sambanis and Schulhofer-Wohl (2019), we find similar results for civil war onset but slightly weaker results for coups. Adding different sets of control variables does not change our insights. Finally, our results remain unaffected when rerunning the analysis with the Log-logistic rather than the Weibull distribution in the outcome stage.

\section{Conclusion}

This paper introduces a novel theory of government formation between leaders of different ethnic groups. Our formal model explores the attempts of leaders to reconcile the contradictory incentives of maximizing the spoils of office and minimizing the risk of losing power through violent conflict. In contrast to earlier work on power sharing, we relax the unitary actor as-

\footnotetext{
${ }^{26}$ Likelihood ratio tests reject the null hypothesis of no difference at $p<.01$.
} 
sumption of governments by conceptualizing them explicitly as coalitions, and of challengers by locating the origin of violent conflict between groups in uncertainty about the cohesion of elites within groups. Where the government formateur is uncertain about the existence and strength of radical sub-groups, armed rebellion becomes more likely. In anticipation of such rebellions, leaders form oversized and grand coalitions to satisfy radical sub-group leaders. When their inclusion into the government coalition and their participation in the respective spoils of office does not satisfy them, our model implies internal coalition conflict or coups.

Empirically, three major findings stand out: First, leaders in ethnically divided societies form oversized and grand coalitions at a much higher rate than expected by classical models of coalition formation, which emphasize the desire of leaders to maximize the spoils of office in small coalitions. Second, coalitions that include fragmented groups are less susceptible to experiencing armed conflict onsets than coalitions around more homogeneous groups. We interpret this finding to support our contention that violent conflict often emerges from fragmented groups. Third, armed rebellions seems to pose as much a risk as coups to the survival of governments - a contrast to insights from authoritarian politics that highlight the higher risk of coups (cf. Svolik 2009; Roessler 2011).

Our findings thus echo similar observations about the effectiveness of concessions to groups with a high threat potential (Wucherpfennig, Hunziker and Cederman 2016; Roessler and Ohls 2018), but more specifically point to internal group fragmentation as its source (see Cunningham 2013). Our work implies that future research needs to pay more attention to the effects of group cohesion on armed conflict onset (also see Larson and Lewis 2018), and that international efforts to stabilize post-conflict environments need to pay as much attention to power sharing within groups as to coalitions between groups (for a related argument, see Lake 2017). Finally, our study calls for far greater attention to coalition formation outside the established democracies in Europe and the Americas. Coalitions in African democracies (Ariotti and Golder 2018) and Southeast Asian autocracies (Pepinsky 2009) follow different patterns than traditional partisan coalitions in Europe and have important effects on regime stability, and as we demonstrate the presence or absence of violent conflict. 


\section{References}

Acemoglu, Daron, Georgy Egorov and Konstantin Sonin. 2008. "Coalition Formation in NonDemocracies." The Review of Economic Studies 75(4):987-1009.

Alesina, Alberto F., Stelios Michalopoulos and Elias Papaioannou. 2016. "Ethnic Inequality." Journal of Political Economy 124(2):428-488.

Ariotti, Margaret H. and Sona N. Golder. 2018. "Partisan Portfolio Allocation in African Democracies." Comparative Political Studies 51(3):341-379.

Arriola, Leonardo R. 2009. "Patronage and Political Stability in Africa." Comparative Political Studies 42(10):1339-1362.

Beck, Nathaniel, Jonathan N. Katz and Richard Tucker. 1998. "Taking Time Seriously: TimeSeries-Cross-Section Analysis with a Binary Dependent Variable." American Journal of Political Science 42(4):1260-1288.

Bogaards, Matthijs. 2014. Democracy and Social Peace in Divided Societies: Exploring Consociational Parties. London, UK: Palgrave Macmillan.

Bormann, Nils-Christian. 2019. “Uncertainty, Cleavages and Ethnic Coalitions.” Journal of Politics 81:471-486.

Bormann, Nils-Christian and Burcu Savun. 2018. "Reputation, Concessions, and Territorial Civil War: Do Ethnic Dominoes Fall, or Don't They?” Journal of Peace Research 55(5):671686.

Bueno de Mesquita, Bruce, Alastair Smith, Randolph M. Siverson and James D. Morrow. 2003. The Logic of Political Survival. Boston: The MIT Press.

Cederman, Lars-Erik, Andreas Wimmer and Brian Min. 2010. "Why Do Ethnic Groups Rebel? New Data and Analysis." World Politics 62(1):87-119.

Chandra, Kanchan. 2012. Constructivist Theories of Ethnic Politics. Oxford, UK: Oxford University Press. 
Chiba, Daina, Lanny W. Martin and Randolph T. Stevenson. 2015. "A Copula Approach to the Problem of Selection Bias in Models of Government Survival.” Political Analysis 23(1):4258.

Cunningham, Kathleen Gallagher. 2013. “Actor Fragmentation and Civil War Bargaining: How Internal Divisions Generate Civil Conflict.” American Journal of Political Science 57(3):659672.

Fearon, James D. 1995. "Rationalist Explanations for War." International Organization 49(3):379-379.

Francois, Patrick, Ilia Rainer and Francesco Trebbi. 2015. "How is Power Shared in Africa?" Econometrica 83(2):465-503.

Gates, Scott, Benjamin AT Graham, Yonatan Lupu, Håvard Strand and Kaare W Strøm. 2016. “Power Sharing, Protection, and Peace.” The Journal of Politics 78(2):512-526.

Gleditsch, Nils Petter, Peter Wallensteen, Mikael Eriksson, Margareta Sollenberg and Havard Strand. 2002. “Armed Conflict 1946-2001: A New Dataset." Journal of Peace Research 39(5):615-637.

Hartzell, Caroline and Matthew Hoddie. 2007. Crafting Peace: Power-Sharing Institutions and the Negotiated Settlement of Civil Wars. University Park, PA: Pennsylvania State University Press.

Hegre, Håvard and Nicholas Sambanis. 2006. "Sensitivity Analysis of Empirical Results on Civil War Onset.” Journal of Conflict Resolution 50(4):508-535.

Hirshleifer, Jack. 2001. The Dark Side of the Force: Economic Foundations of Conflict Theory. New York, NY: Cambridge University Press.

Johnson, Chelsea. 2020. "Power-Sharing, Conflict Resolution, and the Logic of Pre-Emptive Defection.” Journal of Peace Research Online First.:1-15.

Kalyvas, Stathis N. and Laia Balcells. 2010. "International System and Technologies of Rebellion: How the End of the Cold War Shaped Internal Conflict." American Political Science Review 104(03):415-429. 
Kydd, Andrew H and Barbara F Walter. 2006. "The Strategies of Terrorism.” International Security 31(1):49-80.

Lake, Milli. 2017. "Building the Rule of War: Postconflict Institutions and the Micro- Dynamics of Conflict in Eastern DR Congo.” International Organization 71(2):281-315.

Larson, Jennifer M. 2017. "Networks and Interethnic Cooperation." Journal of Politics 79(2):546-559.

Larson, Jennifer M and Janet I Lewis. 2018. "Rumors, Kinship Networks, and Rebel Group Formation.” International Organization 72(4):871-903.

Laver, Michael and Kenneth A. Shepsle. 1996. Making and Breaking Governments: Cabinets and Legislatures in Parliamentary Democracies. Boston, MA: Cambridge University Press.

Lijphart, Arend. 1977. Democracy in Plural Societies: A Comparative Exploration. New Haven, CT: Yale University Press.

Magaloni, Beatrix. 2008. "Credible Power-Sharing and the Longevity of Authoritarian Rule." Comparative Political Studies 41(4-5):715-741.

Martin, Lanny W. and Randolph T. Stevenson. 2001. “Government Formation in Parliamentary Democracies.” American Journal of Political Science 45(1):33-50.

Mattes, Michaela and Burcu Savun. 2009. "Fostering Peace After Civil War: Commitment Problems and Agreement Design.” International Studies Quarterly 53(3):737-759.

McCauley, John F. 2014. "The Political Mobilization of Ethnic and Religious Identities in Africa.” American Political Science Review 108(4):801-816.

Pepinsky, Thomas B. 2009. Economic Crises and the Breakdown of Authoritarian Regimes: Indonesia and Malaysia in Comparative Perspective. New York, NY: Cambridge University Press.

Powell, Jonathan M. and Clayton L. Thyne. 2011. "Global Instances of Coups from 1950 to 2010: A New Dataset." Journal of Peace Research 48(2):249-259.

Ray, Debraj. 2007. A Game-Theoretic Perspective on Coalition Formation. Oxford: Oxford University Press. Kindle file. 
Riker, William H. 1967. The Theory of Political Coalitions. New Haven, CT: Yale University Press.

Roeder, Philip. 2005. Power Dividing as an Alternative to Ethnic Power Sharing. In Sustainable Peace: Power and Democracy after Civil Wars, ed. Philip G. Roeder and Donald Rothchild. Ithaca: Cornell University Press pp. 51-83.

Roessler, Philip and David Ohls. 2018. "Self-Enforcing Power Sharing in Weak States.” International Organization 72(2):423-454.

Roessler, Philip G. 2011. "The Enemy From Within. Personal Rule, Coups, and Civil Wars in Africa." World Politics 63(2):300-346.

Sambanis, Nicholas and Jonah Schulhofer-Wohl. 2019. "Sovereignty Rupture as a Central Concept in Quantitative Measures of Civil War." Journal of Conflict Resolution 63(6):15421578.

Sambanis, Nicholas and Moses Shayo. 2013. "Social Identification and Ethnic Conflict." American Political Science Review 107(2):294-325.

Svolik, Milan W. 2009. "Power Sharing and Leadership Dynamics in Authoritarian Regimes." American Journal of Political Science 53(2):477-494.

Themnér, Lotta and Peter Wallensteen. 2014. “Armed Conflicts, 1946-2013.” Journal of Peace Research 51(4):541-554.

Trivedi, Pravin K. and David M. Zimmer. 2005. Copula Modeling: An Introduction for Practitioners. Boston, MA: Now Publishers.

Vogt, Manuel. 2018. "Ethnic Stratification and the Equilibrium of Inequality: Ethnic Conflict in Postcolonial States.” International organization 72(1):105-137.

Vogt, Manuel, Nils-Christian Bormann, Seraina Ruegger, Lars-Erik Cederman, Philipp Hunziker and Luc Girardin. 2015. "Integrating Data on Ethnicity, Geography, and Conflict: The Ethnic Power Relations Dataset Family." Journal of Conflict Resolution 59(7):1327-1342.

Walter, Barbara F. 2009. "Bargaining Failures and Civil War." Annual Review of Political Science 12:243-261. 
Wucherpfennig, Julian, Philipp Hunziker and Lars-Erik Cederman. 2016. "Who Inherits the State? Colonial Rule and Post-Colonial Conflict." American Journal of Political Science 60(4):882-898. 


\section{Online Appendix to \\ Ethnic Power-Sharing Coalitions and Armed Conflict}

\section{A Table of Contents}

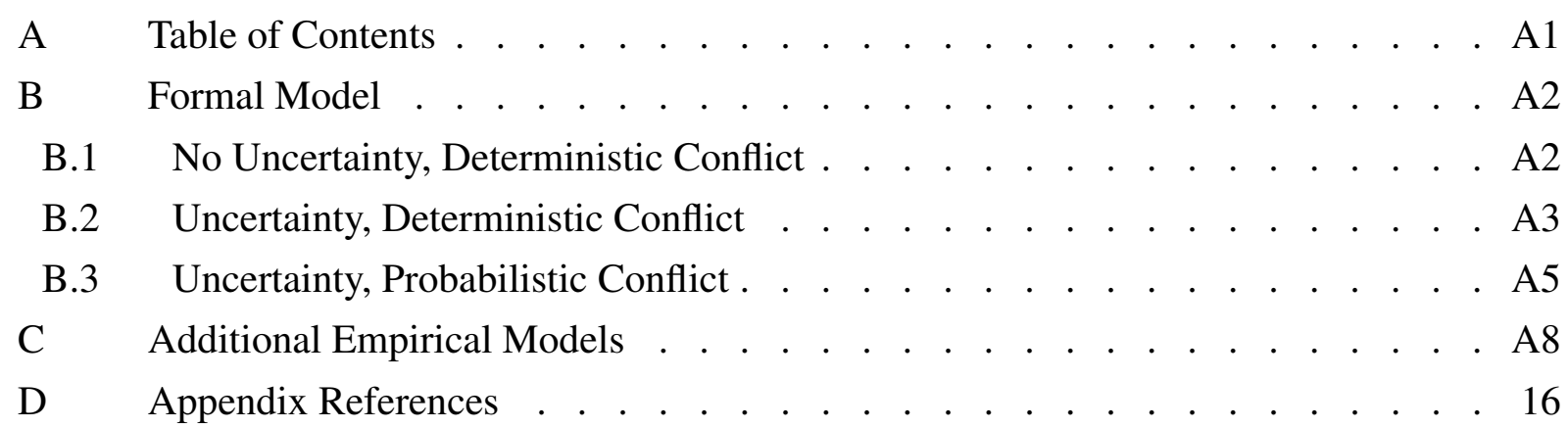




\section{B Formal Model}

\section{B.1 No Uncertainty, Deterministic Conflict}

There are $n$ actors $i, i \in N$. Nature randomly chooses $j \in N$ to act as formateur. The formateur offers a transfer $t_{r}$ to each non-coalition member $r, r \in R$ and $t_{w}, w \in W$ to each coalition member $w$. Note that $j \in W$ and that $W \cup R=N$.

If all $i$ accept the offer $t_{i}$, the result is peace $P$. If any $i$ rejects the offer, the result is conflict $\sim P$. The formateur distributes a finite pie of size 1 . Conflict results in the destruction of a piece of the pie of size $c$. In the case of conflict, payoffs are probabilistically determined as a function of relative group strength. We assume that all groups are of equal size, so each group $i$ has strength $1 / n$.

Claim In equilibrium, the formateur $j$ offers $t_{r}^{*}=\frac{1-c}{n}$ to all actors $i \neq j$, and keeps $t_{j}^{*}=c+\frac{1-c}{n}$ to itself. All $i$ accept the offer and peace prevails.

Proof We will use backwards induction to show that $t_{r}^{*}$ and $t_{j}^{*}$ uniquely solve the formateur's optimization problem and accepting is a best response for all $i$.

We begin with the optimal choice of non-coalition member $r . r$ will accept an offer of $t_{r}$ if

$$
\begin{aligned}
E U_{r}(P) & \geq E U_{r}(\sim P), \\
t_{r} & \geq \frac{1-c}{n}=\widehat{t_{r}} .
\end{aligned}
$$

By construction, coalition members (including $j$ )equally share the remaining pie. Thus, an offer $t_{r}$ results in transfers to coalitions members

$$
t_{w}=\frac{1-(n-k) t_{r}}{k}
$$

where $k=|W|$ is the size of the coalition. Going back in the sequence of play, the formateur's optimal choice of transfers $t_{r}$ and coalition size $k$ that preserves peace is given by

$$
\begin{aligned}
& \arg \max _{k, t_{r}} t_{w}=\frac{1-(n-k) t_{r}}{k} \\
& \text { s.t. } t_{r} \geq \widehat{t_{r}} ; k \in\{1, \ldots, n\} .
\end{aligned}
$$

To show that $t_{r}^{*}=\frac{1-c}{n}$ and $t_{j}^{*}=c+\frac{1-c}{n}$ are the unique solution to the optimization problem, we need to establish that the solution lies at the constraints, i.e. $t_{r}^{*}=\widehat{t_{r}}$, and $k^{*}=1$. We will show that the objective function is decreasing in $t_{r}$ and $k$. Starting with $t_{r}$, the partial derivative is

$$
\begin{aligned}
& \frac{\partial \frac{1-(n-k) t_{r}}{k}}{\partial t}= \frac{k-n}{k} \leq 0 \\
& \text { since } k \leq n
\end{aligned}
$$


Thus, for $k<n$, the objective function is strictly decreasing in $t_{r}$, and constant in $t_{r}$ for $k=n$. Turning to $k$, the partial derivative of the objection function is

$$
\begin{array}{r}
\frac{\partial \frac{1-(n-k) t_{r}}{k}}{\partial k}=\frac{n t_{r}-1}{k^{2}} \leq 0, \\
\text { since } t_{r} \leq 1 / n .
\end{array}
$$

Thus for $t_{r}<1 / n$, the objective function is strictly decreasing in $k$ and constant in $k$ for $t_{r}=1 / n$. Note that $\left\{t_{r}=1 / n, k=n\right\}$ is a critical point giving an interior solution for a global minimum.

The formateur will prefer to offer $t_{r}^{*}$ and set $k^{*}=1$ if

$$
\begin{array}{r}
E U_{j}(P) \geq E U_{j}(\sim P), \\
\frac{1-\left(n-k^{*}\right) t_{r}^{*}}{k^{*}} \geq \frac{1-c}{n}, \\
\frac{1-(n-1) \frac{1-c}{n}}{1} \geq \frac{1-c}{n}, \\
1-n \frac{1-c}{n}+\frac{1-c}{n} \geq \frac{1-c}{n}, \\
c \geq 0,
\end{array}
$$

which is true by assumption.

\section{B.2 Uncertainty, Deterministic Conflict}

Claim The formateur's maximization problem has a global maximum and characterizes a Nash equilibrium to the game.

Proof The proof will proceed by backwards induction. The last movers are subgroups. Let $\underline{i}$ denote a subgroup of $i$, which exists with probability $\pi$. Subgroup $\underline{i}$ has revealed strength $a$ and true strength $b$, with $b>a$. Any subgroup of an actor left out of the coalition will trigger conflict since

$$
\begin{gathered}
E U_{\underline{i}}(\sim P)>E U_{\underline{\underline{i}}}(P, R), \\
\frac{b(1-c)}{n}>\frac{a(1-c)}{n} .
\end{gathered}
$$


Subgroups inside the coalition will trigger if

$$
\begin{array}{r}
E U_{\underline{i}}(\sim P)>E U_{\underline{i}}(P, W), \\
\frac{b(1-c)}{n}>a\left(\frac{c}{k}+\frac{1-c}{n}\right) \\
c<\frac{a k-b k}{-a n+a k-b k} \\
c<\frac{d k}{a n+d k} \\
d>-\frac{a c n}{(c-1) k}
\end{array}
$$

Since the formateur can anticipate $\underline{i}$ 's decision only in expectation, it calculates the probability of $\underline{i}$ triggering as $1-\operatorname{Pr}\left(d \leq-\frac{a c n}{(c-1) k}\right)$. Using the distributional assumption on $d, d \sim U(0,1-a)$, this becomes $1-F_{D}\left(-\frac{a c n}{(c-1) k}\right)=1-\frac{\left(-\frac{a c n}{(c-1) k}\right)}{1-a}$.

Prior to the subgroups, actors $i$ decide whether to accept or reject an offer $t_{r}$ or $t_{w}$. We assume that in case of conflict, any existing subgroup breaks away, leaving the main group $\bar{i}$ to fight by itself. $\bar{i}$ 's conflict payoff therefore becomes

$$
E U_{\bar{i}}=(1-b) \frac{1-c}{n}
$$

When offered $t_{r}^{*}$ as defined in equation 10, $\bar{i}$ 's pre-breakup non-conflict payoff is $(1-a) t_{r}^{*}=$ $(1-a) \frac{1-c}{n}$. Since $b>a$, accepting therefore is $i$ 's best response to any offer $t_{r} \geq t_{r}^{*}$. The same logic extends to members of the governing coalition $w$, who stand to receive $t_{w}^{*} \geq t_{r}^{*}$ from accepting.

Moving up the game tree, the formateur chooses $k$ to solve the maximization problem, which incorporates the best responses as induced by offering $t_{r}^{*}$ and $t_{w}^{*}$ :

$$
\max _{k}(1-\operatorname{Pr}(\sim P))\left(\frac{c}{k}+\frac{1-c}{n}\right)+\operatorname{Pr}(\sim P) \frac{1-c}{n}
$$

where $k \in\{1, \ldots, n\}, c \in[0,1]$, and $\operatorname{Pr}(\sim P)$ are well-defined probabilities mapping $k \rightarrow$ $[0,1]$.

A global maximum exists if the objective function is continuous on a compact set: Compactness of Domain The objective function is defined on $k \in\{1, \ldots, n\}$. Since $k \in$ $\{1, \ldots, n\}$ is bounded and closed, it is compact.

Continuity of Objective Function The function is real valued on a set of integers. Therefore it is continuous. 


\section{B.3 Uncertainty, Probabilistic Conflict}

In the following, we describe changes to the game's setup when introducing probabilistic conflict. Starting from the end, the decision of a subgroup to take up arms remains unchanged, both for groups included and excluded from the governing coalition. Consider the decision calculus for a subgroup $\underline{i}$ that is part of a group which is excluded from the governing coalition. The subgroup will attempt to initiate conflict if

$$
\begin{gathered}
E U_{\underline{i}}(\text { attempt trigger })>E U_{\underline{i}}(\text { no trigger }), \\
(1-p) \frac{a(1-c)}{n}+p \frac{b(1-c)}{n}>\frac{a(1-c)}{n}, \\
\frac{b(1-c)}{n}>\frac{a(1-c)}{n},
\end{gathered}
$$

where $p$ is the probability of statewide conflict. The resulting inequality is identical to inequality (18) and holds always true since $b>a$. As substantive interpretation of $E U_{\underline{i}}$ (attempt trigger), with probability $p$ the subgroup's actions trigger statewide conflict in which it prevails as a function of its true strength $b / n$. The pie is reduced to size $1-c$. With probability $1-p$ the attempt to trigger is not successful, and as a result the subgroup is held to its pre-trigger payoff.

Similarly, consider a subgroup that is part of a group which is included in the governing coalition. It will attempt to start conflict if

$$
\begin{aligned}
& E U_{\underline{i}}(\text { attempt trigger })>E U_{\underline{i}}(\text { no trigger }), \\
&(1-p) a\left(\frac{c}{k}+\frac{1-c}{n}\right)+p \frac{b(1-c)}{n}>a\left(\frac{c}{k}+\frac{1-c}{n}\right), \\
& \frac{b(1-c)}{n}>a\left(\frac{c}{k}+\frac{1-c}{n}\right) \\
& d>-\frac{a c n}{(c-1) k}
\end{aligned}
$$

This is identical to the conflict condition under deterministic conflict initiation in inequality (18). The substantive interpretation is equivalent to those of subgroups outside the governing coalition discussed above.

In the preceding move, the full group $\bar{i}$ needs to decide whether to accept transfers $t_{r}$ or $t_{w}$. Probabilistic conflict initiation adds a weighted non-conflict term to equation $(20),(1-p)(1-$ a) $\frac{1-c}{n}+p(1-b) \frac{1-c}{n}$. Accepting remains the best response, as before. At the top of the sequence of play, the formateur's decision problem remains unchanged in its functional form according to (21). All changes in the model are a function of the conflict probability $\operatorname{Pr}(\sim P)$, which becomes 


$$
\begin{aligned}
\operatorname{Pr}(\sim P)= & \sum_{j=1}^{n} \operatorname{Pr}(j \text { groups unstable })(1-(\operatorname{Pr}(\text { no successful trigger inside coalition }) \\
& * \operatorname{Pr}(\text { no successful trigger outside of coalition }))) \\
= & \sum_{j=1}^{n} \operatorname{Pr}(j \text { groups unstable })\left(1-\left(\sum_{i=0}^{j} \operatorname{Pr}(i \text { unstable groups in coalition })\right.\right. \\
& * \operatorname{Pr}(\text { at least } 1 \text { inside group triggers \& succeeds } \mid \mathrm{i})) \\
& *\left(\sum_{r=0}^{j} \operatorname{Pr}(r \text { unstable groups outside coalition })\right. \\
& * \operatorname{Pr}(\text { at least } 1 \text { outside group succeeds } \mid \mathrm{r})))
\end{aligned}
$$

where $\operatorname{Pr}(j$ groups unstable $)$ follows a binomial distribution, $\operatorname{Pr}(r$ unstable groups inside coalition $)$ and $\operatorname{Pr}(r$ unstable groups outside coalition) follow hypergeometric distributions. The probability $\operatorname{Pr}$ (at least 1 inside group triggers \& succeeds|i) is given by

$$
\sum_{s=0}^{i} \operatorname{Pr}(s \text { groups attempt to trigger }) * \operatorname{Pr}(\text { at least } 1 \text { succeeds })
$$

where $\operatorname{Pr}(s$ groups attempt attempt to trigger $)$ is governed by a binomial distribution with 'success' probability $\frac{\left(-\frac{a c n}{(c-1) k}\right)}{1-a}$ (from equation 8/equation 22), and $\operatorname{Pr}$ (at least 1 succeeds) = $1-(1-p)^{s}$, with $p$ governing the probability that any one triggering group successfully initiates conflict. The equivalent probability for at least one outside groups succeeding to initiate conflict is $\operatorname{Pr}($ at least 1 outside group succeeds $\mid \mathrm{r})=1-(1-p)^{r}$. Also note that we showed above that all unstable groups outside the coalition attempt to trigger with probability 1 (equation 23 ).

The limited ability to initiate conflict can be thought of as introducing an additional element of chance. Accordingly, we add a probabilistic element to the model that governs whether a breakaway group succeeds in triggering conflict. This changes the formateur's decision calculus by modifying the conflict probability (5). Overall, probabilistic conflict initiation decreases the risk of political instability, in turn changing the formateur's risk-return tradeoff. As a result, realized coalitions tend to be smaller. In addition, the overall probability of statewide conflict decreases.

Figure A1 illustrates this. It is based on a scenario with high uncertainty and a large expected number of unstable groups $(\pi=0.8$ with $E$ (unstable $)=5.6)$. The left panel shows coalition behavior with deterministic conflict ( $p=1$ ). The smallest coalition size is 3 , reflecting the high degree of uncertainty, and rises to 7 over the range of conflict costs $c$. Conflict probabilities are very close to 1 and only markedly decrease in a grand coalition scenario as costs pass the $c=0.4$ mark. In the right panel the probability that a breakaway group succeeds in triggering conflict is reduced to $p=0.5$. Across the entire range of $c$, the resulting overall probability of conflict now 
Figure A1: Probabilistic Conflict Initiation
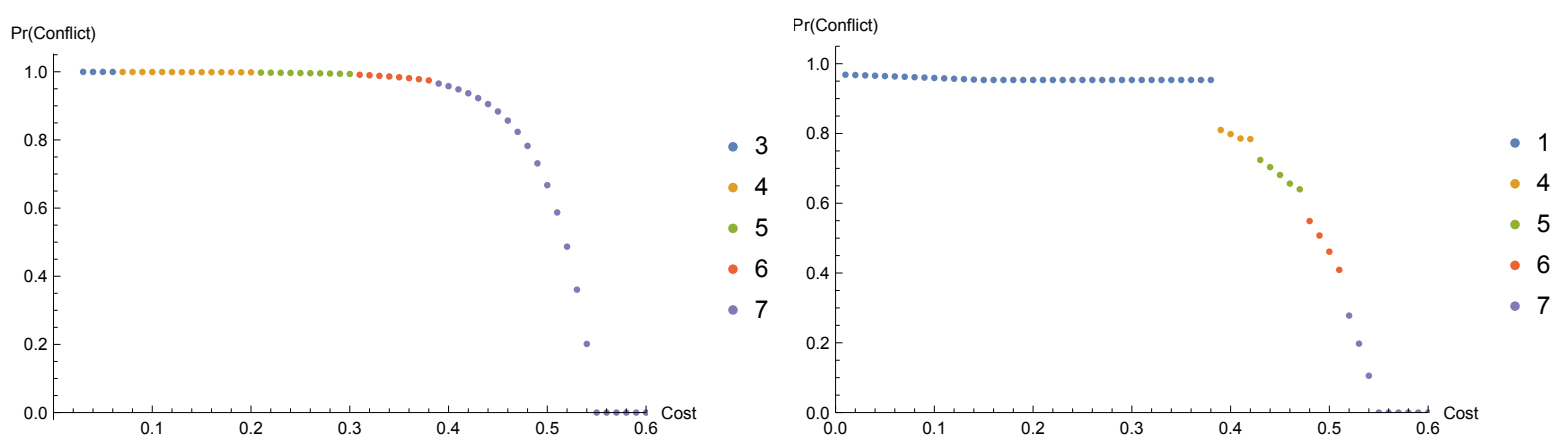

(a) Initiation probability $p=1$

(b) Initiation probability $p=0.5$

$\pi=0.8, n=7, a=0.45$ $\pi=0.8, n=7, a=0.45$

lies below the values from the left panel. The singleton coalition is now the smallest coalition outcome. While conflict is still very likely under singleton coalitions, conflict probabilities are less than in the deterministic scenario. For larger coalitions, the reduction in the probability of conflict is more decisive. For example, for $c=0.4$, conflict risk drops from about 0.95 to 0.8 . Overall, incorporating probabilistic conflict initiation endows the model with more descriptive realism, but it preserves its ability to capture a wide range of predicted conflict probabilities. In addition, while introducing the additional probabilistic element changes point predictions, the patterns identified in the preceding section that give rise to our hypotheses remain the same. 


\section{Additional Empirical Models}

Table A1 shows results from the first-stage logit model of ethnic coalition formation in 137 ethnically divided states between 1946 and 2013. The estimates further support the trends identified in the descriptive analysis. Even when considering all alternative ethnic government compositions that leaders could form, oversized coalitions are still about as likely as single-group majority rule and far more likely than minority and minimum-winning coalitions. Additionally, leaders tend to form coalitions that include the largest group in government, minimize the number of ethnic cleavages, and exclude former rebels. Finally, newly formed governments continue to represent large shares of the population included in previous governments.

Table A1: Conditional logit model of coalition formation in 137 states, 1946-2013

\begin{tabular}{lc}
\hline \hline Single-group majority & $1.785^{* * *}$ \\
& $(0.241)$ \\
Minimum winning coalition & 0.723 \\
& $(0.531)$ \\
Oversized coalition & $1.641^{* * *}$ \\
& $(0.237)$ \\
Largest group & $0.439^{*}$ \\
& $(0.210)$ \\
Member count & -0.020 \\
& $(0.059)$ \\
Ethnic cleavages & $-1.050^{* * *}$ \\
& $(0.099)$ \\
Former rebels included & $-0.541^{* *}$ \\
& $(0.194)$ \\
Past government share & $2.953^{* * *}$ \\
& $(0.289)$ \\
\hline$\ell$ & -1459.067 \\
Formation Opportunities & 542 \\
Potential Governments & $7,270,134$ \\
\hline \hline & ${ }^{*} \mathrm{p}<0.05 ;{ }^{* *} \mathrm{p}<0.01 ;{ }^{* * *} \mathrm{p}<0.001$ \\
Standard errors in parentheses.
\end{tabular}

While our research design tackles one central threat to valid inference, that is, unaccounted selection dynamics, others such as measurement error, omitted variable bias, and model dependency remain. In a recent contribution, Sambanis and Schulhofer-Wohl (2019) discuss the volatility of results in conflict research that solely depend on the UCDP/PRIO Armed Conflict Database (ACD) coding of armed conflicts, on which our analysis also builds. Emphasizing "sovereignty rupture" as the conceptual core of civil war, the authors demonstrate crucial differences between an updated Sambanis' list of civil wars and conflicts in the UCDP/PRIO Armed Conflict Database (ACD), particularly in relation to the timing of onsets. Our analysis could be vulnerable to small changes in coding of the outcome variable due to its selection of the first onset a government experiences and its focus on timing until conflict.

To address this potential weakness, we replace the ACD measure of armed conflict onsets with the Sambanis and Schulhofer-Wohl (SSW) list of civil war onsets. Since no matching to the EPR data currently exist, we also include potentially non-ethnic civil wars in our analysis, which 
Table A2: Armed conflict and coup onset risk after government formation, 1946-2013.

\begin{tabular}{lcccc}
\hline \hline & \multicolumn{2}{c}{ Civil Wars (SSW) } & \multicolumn{2}{c}{ Coup Attempts } \\
& $(5)$ & $(6)$ & $(7)$ & $(8)$ \\
\# of Incl. Segments & -0.246 & $-0.425^{*}$ & -0.134 & -0.0004 \\
& $(0.154)$ & $(0.193)$ & $(0.118)$ & $(0.110)$ \\
\# of Incl. Groups & 0.072 & 0.016 & 0.007 & 0.080 \\
& $(0.059)$ & $(0.089)$ & $(0.062)$ & $(0.052)$ \\
Share of Incl. Pop. & $-1.681^{*}$ & -1.440 & 0.225 & -0.118 \\
& $(0.688)$ & $(0.781)$ & $(0.571)$ & $(0.487)$ \\
Past Rebels in Coal. & $0.596^{*}$ & 0.624 & -0.345 & -0.191 \\
& $(0.302)$ & $(0.353)$ & $(0.328)$ & $(0.256)$ \\
Largest Group & 0.655 & 0.802 & -0.485 & -0.522 \\
& $(0.470)$ & $(0.538)$ & $(0.381)$ & $(0.317)$ \\
Log(GDP p.c.) & $-0.432^{* * *}$ & $-0.454^{* * *}$ & $-0.569^{* * *}$ & $-0.509^{* * *}$ \\
& $(0.096)$ & $(0.101)$ & $(0.077)$ & $(0.070)$ \\
Log(Population) & 0.136 & $0.112^{*}$ & $-0.160^{*}$ & $-0.111^{*}$ \\
& $(0.083)$ & $(0.052)$ & $(0.066)$ & $(0.054)$ \\
Constant & -1.658 & $-1.794^{* * *}$ & $4.319^{* * *}$ & $3.912^{* * *}$ \\
& $(1.496)$ & $(0.062)$ & $(1.230)$ & $(1.053)$ \\
Error Correlation $(\rho)$ & & -0.186 & & $0.194^{* *}$ \\
& & $(0.116)$ & & $(0.075)$ \\
Log(Duration Dependence) & -0.157 & -0.052 & $-0.157^{*}$ & $-0.346^{* *}$ \\
& $(0.086)$ & $(0.098)$ & $(0.066)$ & $(0.106)$ \\
\hline$\ell$ & -1859.180 & -1858.042 & -2045.767 & -2042.677 \\
\# of Countries & 137 & 137 & 137 & 137 \\
\# of Failures & 86 & 86 & 140 & 140 \\
Governments at Risk & 542 & 542 & 542 & 542 \\
Potential Governments & $7,270,134$ & $7,270,134$ & $7,270,134$ & $7,270,134$ \\
\hline \hline
\end{tabular}

${ }^{*} \mathrm{p}<0.05 ;{ }^{* *} \mathrm{p}<0.01 ;{ }^{* * *} \mathrm{p}<0.001$

Displayed estimates are coefficients. Positive values indicate increase in conflict risk.

Standard errors in parentheses. 
do not fit our theoretical argument. Finding similar results as with ethnic armed conflicts should thus be more difficult. We also note that using SSW civil wars as our outcome variable affects our coding of the first coup attempt. Some ethnic armed conflict onsets in our original analysis do not develop into a full-scale civil war with more than 1,000 battle deaths but constitute the first violent challenge an ethnic coalition experiences. Replacing the ACD armed conflicts with SSW civil wars implies that some coups which were previously excluded now become the first conflict a coalition experiences. Overall, seven such cases occur in our dataset.

Table A2 displays the same specification as in Table 1 but now uses the SSW civil wars and recoded coup outcomes. Importantly, we recover the central negative correlation between the number of fragmented groups in a coalition and the risk of civil war onset, when we consider selection dynamics in Model 6. Although our results become slightly weaker when considering non-ethnic civil wars as part of the outcome, including internally fragmented groups still makes coalitions safer for longer, and thus supports $\mathrm{H}_{2}$. We do not find a statistically significant $\rho$ estimate any longer although the coefficient is still negative. We believe this weaker selection effect derives from including non-ethnic civil war onsets in our outcome measure, which cannot fully be addressed by forming ethnic coalitions.

In Model 8, the number of groups in a coalition does not increase coup risk at conventional levels of statistical significance any longer but remains positive in line with $H_{3}$. We still do find evidence for selection on unobservables through the statistically significant and positive $\rho$ parameter. The estimated effects of our control variables remain largely unchanged in Model 5 to 8 .

Omitted variable bias poses another danger to the robustness of our results. In Table A3, we add multiple sets of control variables to the ACD outcome specification. Rather than displaying both models with and without selection dynamics, we only focus on selection models here. More specifically, we add variables that assess the institutional framework of states and changes to their institutions based on the widely-used Polity IV database (Marshall, Jaggers and Gurr 2011) to Models 9 and 12, ethnic fragmentation and polarization indices to Models 10 and 13, and temporal measures to Models 11 and $14 .^{27}$

In all armed conflict specifications (Models 9-11), we continue to find robust evidence in favor of $\mathrm{H}_{2}$ with a strongly negative association between the number of included cleavages and risk of new onsets. Likelihood ratio tests reject the null of equality in favor of the selection model in Models 9-11 with $p<\{.05, .1, .05\}$ respectively, even if the $\rho$ parameter is not always statistically significant at $p<.05$. Neither institutional variables (Model 9), nor the ethnic demography of a country strongly affect the risk of a governments first armed conflict onset (Model 10). We find weak evidence that a new state seems to be at a heightened risk of armed conflicts onsets, but the relationship barely fails to reach the .05 threshold of statistical significance (Model 11). During the cold war, governments faced a lower risk of armed conflict. This finding supports our interpretation that governments could rely on greater outside support from the Soviet Union and the United States during that time.

Turning towards the coup attempt specifications in Models 12-14, we still find strong ev-

\footnotetext{
${ }^{27} \mathrm{We}$ do not display the remaining control variables from earlier specifications but they are included in the estimated models and available in the replication material.
} 
Table A3: Ethnic armed conflict and coup risk after government formation, 1946-2013.

\begin{tabular}{lcccccc}
\hline \hline & \multicolumn{3}{c}{ Ethnic Armed Conflicts } & \multicolumn{3}{c}{ Coup Attempts } \\
& $(9)$ & $(10)$ & $(11)$ & $(12)$ & $(13)$ & $(14)$ \\
\# of incl. cleavages & $-0.629^{* *}$ & $-0.656^{*}$ & $-0.717^{* *}$ & -0.001 & -0.002 & 0.057 \\
& $(0.217)$ & $(0.290)$ & $(0.218)$ & $(0.122)$ & $(0.102)$ & $(0.104)$ \\
\# of incl. groups & 0.030 & 0.019 & 0.045 & 0.114 & 0.018 & $0.097^{*}$ \\
& $(0.136)$ & $(0.121)$ & $(0.112)$ & $(0.060)$ & $(0.100)$ & $(0.048)$
\end{tabular}

Original control variables not shown for reasons of space.

\begin{tabular}{|c|c|c|c|c|c|c|}
\hline Polity & $\begin{array}{c}0.022 \\
(0.025)\end{array}$ & & & $\begin{array}{c}-0.040^{* *} \\
(0.015)\end{array}$ & & \\
\hline Polity $^{2}$ & -0.005 & & & $-0.009^{* * *}$ & & \\
\hline & $(0.005)$ & & & $(0.003)$ & & \\
\hline Foreign occupation & $\begin{array}{l}-0.449 \\
(1.281)\end{array}$ & & & $\begin{array}{l}-0.758 \\
(0.738)\end{array}$ & & \\
\hline Democratization & $\begin{array}{l}-0.046 \\
(0.064)\end{array}$ & & & $\begin{array}{c}0.033 \\
(0.020)\end{array}$ & & \\
\hline Autocratization & $\begin{array}{l}-0.027 \\
(0.110)\end{array}$ & & & $\begin{array}{c}0.145^{* * *} \\
(0.023)\end{array}$ & & \\
\hline Ethnic fractionalization & & $\begin{array}{c}0.621 \\
(1.532)\end{array}$ & & & $\begin{array}{c}1.457 \\
(0.784)\end{array}$ & \\
\hline Ethnic polarization & & $\begin{array}{c}0.005 \\
(0.879)\end{array}$ & & & $\begin{array}{l}-0.097 \\
(0.423)\end{array}$ & \\
\hline New state & & & $\begin{array}{c}0.621 \\
(0.407)\end{array}$ & & & $\begin{array}{c}-0.970^{* * *} \\
(0.210)\end{array}$ \\
\hline Cold war & & & $\begin{array}{c}-0.865^{* *} \\
(0.326)\end{array}$ & & & $\begin{array}{c}0.578^{* *} \\
(0.194)\end{array}$ \\
\hline Peace years & & & $\begin{array}{l}-0.001 \\
(0.013)\end{array}$ & & & $\begin{array}{l}-0.011 \\
(0.007)\end{array}$ \\
\hline Log(Duration Dependence) & $\begin{array}{c}0.056 \\
(0.106)\end{array}$ & $\begin{array}{c}0.034 \\
(0.114)\end{array}$ & $\begin{array}{c}0.073 \\
(0.122)\end{array}$ & $\begin{array}{c}-0.319^{* *} \\
(0.124)\end{array}$ & $\begin{array}{c}-0.479^{* * *} \\
(0.143)\end{array}$ & $\begin{array}{c}-0.408^{* * *} \\
(0.110)\end{array}$ \\
\hline Error Correlation $(\rho)$ & $\begin{array}{l}-0.336 \\
(0.178)\end{array}$ & $\begin{array}{l}-0.302 \\
(0.177)\end{array}$ & $\begin{array}{c}-0.368^{*} \\
(0.179)\end{array}$ & $\begin{array}{l}0.222^{*} \\
(0.093)\end{array}$ & $\begin{array}{c}0.284^{* * *} \\
(0.079)\end{array}$ & $\begin{array}{c}0.255^{* * *} \\
(0.073)\end{array}$ \\
\hline Constant & $\begin{array}{l}-4.330 \\
(2.909)\end{array}$ & $\begin{array}{c}-5.338^{* * *} \\
(0.622)\end{array}$ & $\begin{array}{l}-5.252 \\
(2.696)\end{array}$ & $\begin{array}{c}2.927^{* * *} \\
(0.151)\end{array}$ & $\begin{array}{c}2.271 \\
(2.539)\end{array}$ & $\begin{array}{c}4.305^{* * *} \\
(1.083)\end{array}$ \\
\hline$\ell$ & -1792.473 & -1794.338 & -1790.418 & -1991.573 & -2007.361 & -1996.16 \\
\hline \# of Countries & 137 & 137 & 137 & 137 & 137 & 137 \\
\hline \# of Failures & 74 & 74 & 74 & 133 & 133 & 133 \\
\hline Governments at Risk & 542 & 542 & 542 & 542 & 542 & 542 \\
\hline Potential Governments & $7,270,134$ & $7,270,134$ & $7,270,134$ & $7,270,134$ & $7,270,134$ & $7,270,134$ \\
\hline
\end{tabular}

${ }^{*} \mathrm{p}<0.05 ;{ }^{* *} \mathrm{p}<0.01 ;{ }^{* * *} \mathrm{p}<0.001$

Displayed estimates are coefficients. Positive values indicate increase in risk of conflict/coup onset. Standard errors in parentheses. 
idence for selection effects in the $\rho$ parameter despite the newly added control variables that exert stronger impact on attempted coups than on armed conflicts. Established democracies have a much reduced coup risk but slides towards the autocratic end of the Polity scale increase coup occurrence (Model 12). Ethnic fractionalization and polarization do not have any meaningful influence on risk of the first coup (Model 13), but the first two years after independence decrease the likelihood of coup attempts. In contrast, ethnic government coalitions were at a much higher risk to experience coup attempts during the Cold War, a finding that resonates with earlier work (Roessler 2011, 308).

Model uncertainty is our final concern. Given the unconventional modeling of conflict risk via parametric duration models, we need to ensure that our results do not rely on using the Weibull distribution in the duration stage. Therefore, we re-estimated all models reported above with the Log-logistic distribution in the conflict stage. ${ }^{28}$ One central advantage of the Log-logistic distribution is that it allows a non-monotonic hazard rate. In other words, the underlying hazard of conflict can first rise and then fall or vice versa. A drawback of the Loglogistic models is that they do not allow us to display hazard betas. Instead, we need to display the estimated coefficients in the accelerated failure time metric, which means that positive coefficients indicate increased duration until the first armed conflict or coup onset, but a decreased onset risk. The interpretation of estimated coefficients in the Log-logistic models is thus the inverse of the Weibull models.

The results from these robustness tests do not show any meaningful difference from the Weibull models. In all specifications, we recover the negative relationship between the internal fragmentation of governments and armed conflict risk, or a positive correlation between more fragmented governments and an increased time until the first conflict onset. We also find a consistent preference for the selection specification over models that ignore selection dynamics.

\footnotetext{
${ }^{28}$ We display Weibull models in the main text because they exhibit overall greater model fit.
} 
Table A4: Time until conflict after government formation in ethnically divided societies, 1946-2013 (log-logistic distribution).

\begin{tabular}{lcccc}
\hline \hline & \multicolumn{2}{c}{ Ethnic Armed Conflicts } & \multicolumn{2}{c}{ Coup Attempts } \\
& $(1)$ & $(2)$ & $(3)$ & $(4)$ \\
\hline \# of Incl. Segments & $0.387^{*}$ & $0.604^{* *}$ & 0.248 & -0.082 \\
& $(0.194)$ & $(0.215)$ & $(0.145)$ & $(0.180)$ \\
\# of Incl. Groups & $-0.130^{*}$ & -0.039 & -0.007 & $-0.214^{*}$ \\
& $(0.066)$ & $(0.091)$ & $(0.075)$ & $(0.103)$ \\
Share of Incl. Pop. & $2.093^{*}$ & 1.371 & -0.428 & 0.788 \\
& $(0.922)$ & $(0.974)$ & $(0.743)$ & $(0.818)$ \\
Past Rebels in Coal. & $-0.915^{*}$ & $-0.844^{*}$ & 0.307 & 0.154 \\
& $(0.369)$ & $(0.378)$ & $(0.384)$ & $(0.380)$ \\
Largest Group & -0.803 & -0.858 & 0.686 & 0.854 \\
& $(0.637)$ & $(0.631)$ & $(0.490)$ & $(0.480)$ \\
Log(GDP p.c.) & $0.505^{* * *}$ & $0.462^{* *}$ & $0.676^{* * *}$ & $0.789^{* * *}$ \\
& $(0.122)$ & $(0.148)$ & $(0.096)$ & $(0.106)$ \\
Log(Population) & $-0.330^{* *}$ & $-0.265^{*}$ & $0.176^{*}$ & 0.145 \\
& $(0.104)$ & $(0.108)$ & $(0.083)$ & $(0.094)$ \\
Constant & $4.453^{*}$ & $4.479^{*}$ & $-5.520^{* * *}$ & $-7.272^{* * *}$ \\
& $(1.895)$ & $(2.161)$ & $(1.538)$ & $(1.696)$ \\
Error Correlation $(\rho)$ & & $0.296^{*}$ & & $-0.478^{* * *}$ \\
& & $(0.139)$ & & $(0.122)$ \\
Log(Duration Dependence) & -0.028 & 0.082 & 0.022 & $-0.160^{*}$ \\
& $(0.094)$ & $(0.098)$ & $(0.070)$ & $(0.076)$ \\
\hline$\ell$ & -1796.078 & -1793.422 & -2013.081 & -2007.733 \\
\# of Countries & 137 & 137 & 137 & 137 \\
\# of Failures & 74 & 74 & 133 & 133 \\
Governments at Risk & 542 & 542 & 542 & 542 \\
Potential Governments & $7,270,134$ & $7,270,134$ & $7,270,134$ & $7,270,134$ \\
\hline \hline
\end{tabular}

${ }^{*} \mathrm{p}<0.05 ;{ }^{* *} \mathrm{p}<0.01 ;{ }^{* * *} \mathrm{p}<0.001$

Displayed estimates are coefficients. Positive values indicate increase in duration. Standard errors in parentheses. 
Table A5: Time to conflict after government formation in ethnically divided societies, 1946-2013 (log-logistic distribution).

\begin{tabular}{lcccc}
\hline \hline & \multicolumn{2}{c}{ Civil Wars (SSW) } & \multicolumn{2}{c}{ Coup Attempts } \\
& $(5)$ & $(6)$ & $(7)$ & $(8)$ \\
\hline \# of Incl. Segments & 0.329 & $0.482^{* *}$ & 0.202 & -0.048 \\
& $(0.180)$ & $(0.180)$ & $(0.143)$ & $(0.167)$ \\
\# of Incl. Groups & -0.086 & -0.017 & 0.001 & -0.140 \\
& $(0.070)$ & $(0.088)$ & $(0.074)$ & $(0.092)$ \\
Share of Incl. Pop. & $2.084^{*}$ & $1.608^{* * *}$ & -0.207 & 0.671 \\
& $(0.866)$ & $(0.473)$ & $(0.717)$ & $(0.781)$ \\
Past Rebels in Coal. & -0.626 & -0.587 & 0.344 & 0.137 \\
& $(0.366)$ & $(0.383)$ & $(0.367)$ & $(0.352)$ \\
Largest Group & -0.838 & $-0.931^{*}$ & 0.594 & 0.714 \\
& $(0.597)$ & $(0.435)$ & $(0.470)$ & $(0.452)$ \\
Log(GDP p.c.) & $0.512^{* * *}$ & $0.490^{* * *}$ & $0.679^{* * *}$ & $0.738^{* * *}$ \\
& $(0.114)$ & $(0.099)$ & $(0.094)$ & $(0.086)$ \\
Log(Population) & -0.152 & -0.118 & $0.206^{*}$ & $0.156^{* *}$ \\
& $(0.097)$ & $(0.062)$ & $(0.080)$ & $(0.048)$ \\
Constant & 1.292 & $1.468^{*}$ & $-6.095^{* * *}$ & $-6.804^{* * *}$ \\
& $(1.771)$ & $(0.630)$ & $(1.493)$ & $(0.314)$ \\
Error Correlation $(\rho)$ & & 0.193 & & $-0.370^{* *}$ \\
& & $(0.120)$ & & $(0.129)$ \\
Log(Duration Dependence) & -0.045 & 0.021 & 0.030 & -0.069 \\
& $(0.087)$ & $(0.091)$ & $(0.068)$ & $(0.077)$ \\
\hline$\ell$ & -1857.658 & -1856.476 & -2041.009 & -2036.31 \\
\# of Countries & 137 & 137 & 137 & 137 \\
\# of Failures & 86 & 86 & 140 & 140 \\
Governments at Risk & 542 & 542 & 542 & 542 \\
Potential Governments & $7,270,134$ & $7,270,134$ & $7,270,134$ & $7,270,134$ \\
\hline \hline
\end{tabular}

${ }^{*} \mathrm{p}<0.05 ;{ }^{* *} \mathrm{p}<0.01 ;{ }^{* * *} \mathrm{p}<0.001$

Displayed estimates are coefficients. Positive values indicate increase in duration.

Standard errors in parentheses. 
Table A6: Time to conflict after government formation in ethnically divided societies, 1946-2013 (log-logistic distribution).

\begin{tabular}{lcccccc}
\hline \hline & \multicolumn{3}{c}{ Ethnic Armed Conflicts } & \multicolumn{3}{c}{ Coup Attempts } \\
& $(9)$ & $(10)$ & $(11)$ & $(12)$ & $(13)$ & $(14)$ \\
\hline \# of incl. cleavages & $0.584^{* *}$ & $0.616^{* *}$ & $0.654^{* *}$ & -0.171 & -0.006 & -0.096 \\
& $(0.216)$ & $(0.215)$ & $(0.204)$ & $(0.170)$ & $(0.166)$ & $(0.154)$
\end{tabular}

Original control variables not shown for reasons of space.

\begin{tabular}{|c|c|c|c|c|c|c|}
\hline Polity & $\begin{array}{l}-0.018 \\
(0.022)\end{array}$ & & & $\begin{array}{c}0.056^{* *} \\
(0.018)\end{array}$ & & \\
\hline \multirow[t]{2}{*}{ Polity $^{2}$} & 0.004 & & & $0.011^{* *}$ & & \\
\hline & $(0.004)$ & & & $(0.004)$ & & \\
\hline \multirow[t]{2}{*}{ Foreign occupation } & 0.437 & & & 1.331 & & \\
\hline & $(1.172)$ & & & $(0.903)$ & & \\
\hline \multirow[t]{2}{*}{ Democratization } & 0.050 & & & -0.033 & & \\
\hline & $(0.058)$ & & & $(0.028)$ & & \\
\hline \multirow[t]{2}{*}{ Autocratization } & 0.028 & & & $-0.216^{* * *}$ & & \\
\hline & $(0.103)$ & & & $(0.039)$ & & \\
\hline \multirow[t]{2}{*}{ Ethnic fractionalization } & & -0.734 & & & $-2.460^{* *}$ & \\
\hline & & $(1.201)$ & & & $(0.843)$ & \\
\hline \multirow[t]{2}{*}{ Ethnic polarization } & & -0.040 & & & 0.090 & \\
\hline & & $(0.876)$ & & & $(0.557)$ & \\
\hline \multirow[t]{2}{*}{ New state } & & & -0.550 & & & $1.567^{* * *}$ \\
\hline & & & $(0.351)$ & & & $(0.306)$ \\
\hline \multirow[t]{2}{*}{ Cold war } & & & $0.799^{*}$ & & & $-0.867^{* * *}$ \\
\hline & & & $(0.314)$ & & & $(0.260)$ \\
\hline \multirow[t]{2}{*}{ Peace years } & & & 0.003 & & & 0.012 \\
\hline & & & $(0.012)$ & & & $(0.010)$ \\
\hline \multirow[t]{2}{*}{ Constant } & $4.115^{*}$ & $5.148^{*}$ & $4.739^{* * *}$ & $-4.689^{* *}$ & $-4.348^{* *}$ & $-7.283^{* * *}$ \\
\hline & $(1.908)$ & $(2.077)$ & $(0.225)$ & $(1.520)$ & $(1.491)$ & $(0.311)$ \\
\hline \multirow[t]{2}{*}{ Log(Duration Dependence) } & 0.098 & 0.082 & 0.114 & -0.017 & -0.095 & -0.048 \\
\hline & $(0.102)$ & $(0.103)$ & $(0.100)$ & $(0.074)$ & $(0.075)$ & $(0.082)$ \\
\hline \multirow[t]{2}{*}{ Error Correlation $(\rho)$} & $0.301^{*}$ & 0.255 & $0.315^{*}$ & $-0.447^{* * *}$ & $-0.519^{* * *}$ & $-0.470^{* *}$ \\
\hline & $(0.149)$ & $(0.158)$ & $(0.145)$ & $(0.110)$ & $(0.117)$ & $(0.159)$ \\
\hline$\ell$ & -1791.485 & -1793.031 & -1789.346 & -1982.477 & -2000.52 & -1988.011 \\
\hline \# of Countries & 137 & 137 & 137 & 137 & 137 & 137 \\
\hline \# of Failures & 74 & 74 & 74 & 133 & 133 & 133 \\
\hline Governments at Risk & 542 & 542 & 542 & 542 & 542 & 542 \\
\hline Potential Governments & $7,270,134$ & $7,270,134$ & $7,270,134$ & $7,270,134$ & $7,270,134$ & $7,270,134$ \\
\hline
\end{tabular}

${ }^{*} \mathrm{p}<0.05 ;{ }^{* *} \mathrm{p}<0.01 ;{ }^{* * *} \mathrm{p}<0.001$

Displayed estimates are coefficients. Positive values indicate increase in duration. Standard errors in parentheses. 


\section{Appendix References}

Marshall, Monty G., Keith Jaggers and Ted Robert Gurr. 2011. The Polity IV Project - Political Regime Characteristics and Transitions, 1800-2010. Technical report Center for Systemic Peace.

URL: www.systemicpeace.org/polity/polity4.htm

Roessler, Philip G. 2011. “The Enemy From Within. Personal Rule, Coups, and Civil Wars in Africa." World Politics 63(2):300-346.

Sambanis, Nicholas and Jonah Schulhofer-Wohl. 2019. "Sovereignty Rupture as a Central Concept in Quantitative Measures of Civil War." Journal of Conflict Resolution 63(6):15421578. 